\title{
Prevention and Control of Seasonal Influenza with Vaccines: Recommendations of the Advisory Committee on Immunization Practices- United States, 2018-19 Influenza Season
}




\section{CONTENTS}

Introduction . .1

Methods 2

Primary Changes and Updates in the Recommendations. ....4 4

Recommendations for the Use of Influenza Vaccines, 2018-19...........4 Influenza Vaccine Composition and Available Products....................... 11 Additional Sources for Information Regarding Influenza and Influenza Vaccines 14

References. 16

\section{CDC Adoption of ACIP Recommendations for MMWR Recommendations and Reports, MMWR Policy Notes, and Immunization Schedules (Child/Adolescent, Adult)}

Recommendations for routine use of vaccines in children, adolescents, and adults are developed by the Advisory Committee on Immunization Practices (ACIP). ACIP is chartered as a federal advisory committee to provide expert external advice and guidance to the Director of CDC on use of vaccines and related agents for the control of vaccinepreventable diseases in the civilian population of the United States. Recommendations for routine use of vaccines in children and adolescents are harmonized to the greatest extent possible with recommendations made by the American Academy of Pediatrics (AAP), the American Academy of Family Physicians (AAFP), and the American College of Obstetricians and Gynecologists (ACOG). Recommendations for routine use of vaccines in adults are harmonized with recommendations of AAFP, ACOG, and the American College of Physicians (ACP). ACIP recommendations approved by the CDC Director become agency guidelines on the date published in the Morbidity and Mortality Weekly Report (MMWR). Additional information is available at https://www.cdc.gov/vaccines/acip.

The MMWR series of publications is published by the Center for Surveillance, Epidemiology, and Laboratory Services, Centers for Disease Control and Prevention (CDC), U.S. Department of Health and Human Services, Atlanta, GA 30329-4027.

Suggested citation: [Author names; first three, then et al., if more than six.] [Title]. MMWR Recomm Rep 2018;67(No. RR-\#):[inclusive page numbers].

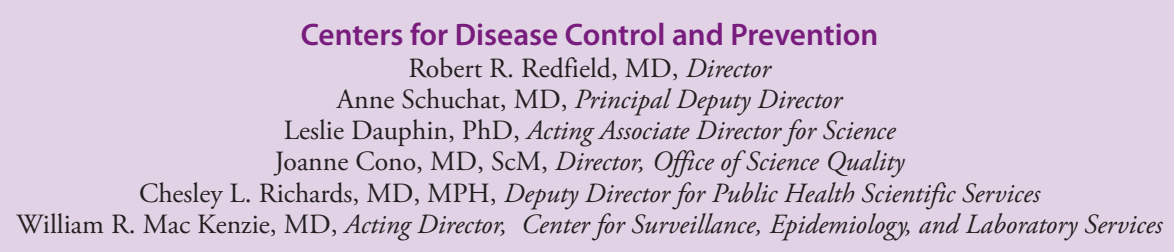

MMWR Editorial and Production Staff (Serials)

Charlotte K. Kent, PhD, MPH, Acting Editor in Chief, Executive Editor Christine G. Casey, MD, Editor

Mary Dott, MD, MPH, Online Editor

Teresa F. Rutledge, Managing Editor

David C. Johnson, Lead Technical Writer-Editor

Jeffrey D. Sokolow, MA, Project Editor

Matthew L. Boulton, MD, MPH

Virginia A. Caine, MD

Katherine Lyon Daniel, $\mathrm{PhD}$

Jonathan E. Fielding, MD, MPH, MBA

David W. Fleming, MD
MMWR Editorial Board

Timothy F. Jones, MD, Chairman William E. Halperin, MD, DrPH, MPH Robin Ikeda, MD, MPH

Phyllis Meadows, PhD, MSN, RN

Jewel Mullen, MD, MPH, MPA Jeff Niederdeppe, PhD
Martha F. Boyd, Lead Visual Information Specialist Maureen A. Leahy, Julia C. Martinroe, Stephen R. Spriggs, Tong Yang, Visual Information Specialists

Quang M. Doan, MBA, Phyllis H. King, Terraye M. Starr, Moua Yang, Information Technology Specialists

\author{
Patricia Quinlisk, MD, MPH \\ Patrick L. Remington, MD, MPH \\ Carlos Roig, MS, MA \\ William Schaffner, MD
}




\title{
Prevention and Control of Seasonal Influenza with Vaccines: Recommendations of the Advisory Committee on Immunization Practices-United States, 2018-19 Influenza Season
}

\author{
Lisa A. Grohskopf, $\mathrm{MD}^{1}$ \\ Leslie Z. Sokolow, MSc, MPH ${ }^{1,2}$ \\ Karen R. Broder, $\mathrm{MD}^{3}$ \\ Emmanuel B. Walter, MD 4 \\ Alicia M. Fry, $\mathrm{MD}^{1}$ \\ Daniel B. Jernigan, $\mathrm{MD}^{1}$ \\ ${ }^{1}$ Influenza Division, National Center for Immunization and Respiratory Diseases, CDC \\ ${ }^{2}$ Battelle Memorial Institute, Atlanta, Georgia \\ 3 Immunization Safety Office, National Center for Emerging and Zoonotic Infectious Diseases, CDC \\ ${ }^{4}$ Duke University School of Medicine, Durham, North Carolina
}

\begin{abstract}
Summary
This report updates the 2017-18 recommendations of the Advisory Committee on Immunization Practices (ACIP) regarding the use of seasonal influenza vaccines in the United States (MMWR Recomm Rep 2017;66[No. RR-2]). Routine annual influenza vaccination is recommended for all persons aged $\geq 6$ months who do not have contraindications. A licensed, recommended, and age-appropriate vaccine should be used. Inactivated influenza vaccines (IIVs), recombinant influenza vaccine (RIV), and live attenuated influenza vaccine (LAIV) are expected to be available for the 2018-19 season. Standard-dose, unadjuvanted, inactivated influenza vaccines will be available in quadrivalent (IIV4) and trivalent (IIV3) formulations. Recombinant influenza vaccine (RIV4) and live attenuated influenza vaccine (LAIV4) will be available in quadrivalent formulations. High-dose inactivated influenza vaccine (HD-IIV3) and adjuvanted inactivated influenza vaccine (aIIV3) will be available in trivalent formulations.

Updates to the recommendations described in this report reflect discussions during public meetings of ACIP held on October 25, 2017; February 21, 2018; and June 20, 2018. New and updated information in this report includes the following four items. First, vaccine viruses included in the 2018-19 U.S. trivalent influenza vaccines will be an A/Michigan/45/2015 (H1N1) pdm09-like virus, an A/Singapore/INFIMH-16-0019/2016 (H3N2)-like virus, and a B/Colorado/06/2017-like virus (Victoria lineage). Quadrivalent influenza vaccines will contain these three viruses and an additional influenza B vaccine virus, a B/Phuket/3073/2013-like virus (Yamagata lineage). Second, recommendations for the use of LAIV4 (FluMist Quadrivalent) have been updated. Following two seasons (2016-17 and 2017-18) during which ACIP recommended that LAIV4 not be used, for the 2018-19 season, vaccination providers may choose to administer any licensed, age-appropriate influenza vaccine (IIV, RIV4, or LAIV4). LAIV4 is an option for those for whom it is appropriate. Third, persons with a history of egg allergy of any severity may receive any licensed, recommended, and age-appropriate influenza vaccine (IIV, RIV4, or LAIV4). Additional recommendations concerning vaccination of egg-allergic persons are discussed. Finally, information on recent licensures and labeling changes is discussed, including expansion of the age indication for Afluria Quadrivalent (IIV4) from $\geq 18$ years to $\geq 5$ years and expansion of the age indication for Fluarix Quadrivalent (IIV4), previously licensed for $\geq 3$ years, to $\geq 6$ months.

This report focuses on the recommendations for use of vaccines for the prevention and control of influenza during the 2018-19 season in the United States. A Background Document containing further information and a brief summary of these recommendations are available at https://www.cdc.gov/vaccines/hcplacip-recs/vacc-specificlflu.html.

These recommendations apply to U.S.-licensed influenza vaccines used within Food and Drug Administration-licensed indications. Updates and other information are available at CDC's influenza website (https://www.cdc.gov/flu). Vaccination and health care providers should check CDC's influenza website periodically for additional information.
\end{abstract}

Corresponding author: Lisa A. Grohskopf, Influenza Division, National Center for Immunization and Respiratory Diseases, CDC. Telephone: 404-639-2552; E-mail: Lkg6@cdc.gov.

\section{Introduction}

Influenza viruses typically circulate in the United States annually, most commonly from late fall through early spring. Most persons who contract influenza will recover without 
sequelae. However, influenza can cause serious illness, hospitalization, and death, particularly among older adults, very young children, pregnant women, and those with certain chronic medical conditions (1-6).

Routine annual influenza vaccination for all persons aged $\geq 6$ months who do not have contraindications has been recommended by CDC and CDC's Advisory Committee on Immunization Practices (ACIP) since 2010 (7). This report updates the 2017-18 ACIP recommendations regarding the use of seasonal influenza vaccines (8) and provides recommendations and guidance for vaccine providers regarding the use of influenza vaccines for the 2018-19 season. A variety of different formulations of influenza vaccine are available (Table 1). Contraindications and precautions to the use of influenza vaccines are summarized (Table 2). Abbreviations are used in this report to denote the various types of vaccines (Box).

This report focuses on the recommendations for use of influenza vaccines for the prevention and control of influenza during the 2018-19 season in the United States. A summary of these recommendations and a Background Document containing additional information on influenza-associated illnesses and influenza vaccines are available at https://www. cdc.gov/vaccines/hcp/acip-recs/vacc-specific/flu.html.

\section{Methods}

ACIP provides annual recommendations for the use of influenza vaccines for the prevention and control of influenza. The ACIP Influenza Work Group meets by teleconference once to twice per month throughout the year. Work Group membership includes several voting members of ACIP and representatives of ACIP Liaison Organizations.* Discussions include topics such as influenza surveillance, vaccine effectiveness and safety, vaccine coverage, program feasibility, cost-effectiveness, and vaccine supply. Presentations are requested from invited experts, and published and unpublished data are discussed.

In general, the Background Document is updated to reflect recent additions to the literature related to the following: 1) recommendations that were made in previous seasons, 2) changes in the viral antigen composition of seasonal influenza vaccines, and 3) minor changes in guidance for the use of influenza vaccines (e.g., guidance for timing of vaccination and other programmatic issues, guidance for dosage in specific populations, guidance for selection of vaccines for specific populations that are already recommended for vaccination, and changes that reflect use that is consistent with Food and Drug

\footnotetext{
*A list of Work Group members may be found on page 20 of this report. A Disclosure of Relationships may be found on page 19.
}

Administration [FDA]-licensed indications and prescribing information). The summary included in the Background Document for such topics is not a systematic review but is intended to provide a broad overview of current literature. In general, systematic review and evaluation of the evidence using the Grading of Recommendations Assessment, Development and Evaluation (GRADE) approach is performed for new recommendations or substantial changes in the recommendations (e.g., expansion of the recommendation for influenza vaccination to new populations not previously recommended for vaccination or potential preferential recommendations for specific vaccines).

Updates and changes to the recommendations described in this report are of four types: 1) the vaccine virus composition for 2018-19 U.S. seasonal influenza vaccines; 2) a recommendation for the 2018-19 season that LAIV4 is an option for influenza vaccination of persons for whom it is appropriate; 3) a recommendation that persons with a history of egg allergy may receive any licensed, recommended, and age-appropriate influenza vaccine (IIV, RIV4, or LAIV4; and 4) recent regulatory actions, including new vaccine licensures and labeling changes for previously licensed vaccines. Information relevant to these changes included the following:

1. Recommendations for the composition of Northern Hemisphere influenza vaccines are made by the World Health Organization (WHO), which organizes a consultation, generally in February of each year. Surveillance data are reviewed and candidate vaccine viruses are discussed. A summary of the WHO meeting for selection of the 2018-19 Northern Hemisphere vaccine viruses is available at http://www.who.int/ influenza/vaccines/virus/recommendations/201802_ recommendation.pdf. Subsequently, FDA, which has regulatory authority over vaccines in the United States, convenes a meeting of its Vaccines and Related Biological Products Advisory Committee (VRBPAC). This committee considers the recommendations of WHO, reviews and discusses similar data, and makes a final decision regarding vaccine virus composition for influenza vaccines licensed and marketed in the United States. A summary of the FDA VRBPAC meeting of March 1, 2018, at which the composition of the 2018-19 U.S. influenza vaccines was discussed, is available at https:/www.fda.gov/downloads/ AdvisoryCommittees/CommitteesMeetingMaterials/ BloodVaccinesandOtherBiologics/VaccinesandRelated BiologicalProductsAdvisoryCommittee/UCM602610.pdf.

2. Regarding the recommendation for the 2018-19 season that LAIV4 is an option for influenza vaccination of those for whom it is appropriate, ACIP reviewed data from three sources in February 2018. Two were evaluations of previous 


\begin{tabular}{|c|c|c|c|c|c|c|c|c|}
\hline $\begin{array}{l}\text { Trade name } \\
\text { (Manufacturer) }\end{array}$ & Presentation & $\begin{array}{c}\text { Age } \\
\text { indication }\end{array}$ & $\begin{array}{l}\text { HA (IIVs and } \\
\text { RIV4) or virus } \\
\text { count (LAIV4) } \\
\text { per dose (each } \\
\text { vaccine virus) }\end{array}$ & $\begin{array}{c}\text { Egg-grown } \\
\text { virus, }{ }^{\dagger} \text { cell } \\
\text { culture-grown } \\
\text { virus, or } \\
\text { recombinant HA }\end{array}$ & $\begin{array}{l}\text { Adjuvanted } \\
\text { (Yes/No) }\end{array}$ & $\begin{array}{l}\text { Latex } \\
\text { (Yes/No) }\end{array}$ & Route & $\begin{array}{l}\text { Thimerosal } \\
\text { (Yes/No) } \\
\text { If Yes, mercury } \\
\mu \mathrm{g} / 0.5 \mathrm{~mL}\end{array}$ \\
\hline \multicolumn{9}{|c|}{ Quadrivalent IIVs (IIV4s)—Standard Dose-Contain inactivated virus } \\
\hline $\begin{array}{l}\text { Afluria Quadrivalent } \\
\text { (Seqirus) }\end{array}$ & $\begin{array}{l}0.5 \mathrm{~mL} \text { PFS } \\
5.0 \mathrm{~mL} \text { MDV }\end{array}$ & $\begin{array}{l}\geq 5 \text { yrs } \\
\geq 5 \text { yrs (needle/ } \\
\text { syringe) } \\
18 \text { through } 64 \text { yrs } \\
\text { (jet injector) }\end{array}$ & $15 \mu \mathrm{g} / 0.5 \mathrm{~mL}$ & Egg & No & No & $\mathrm{I} \mathrm{M}^{\S}$ & $\begin{array}{c}\text { No } \\
\text { Yes (24.5) }\end{array}$ \\
\hline $\begin{array}{l}\text { Fluarix Quadrivalent } \\
\text { (GlaxoSmithKline) }\end{array}$ & $0.5 \mathrm{~mL}$ PFS & $\geq 6 \mathrm{mos}$ & $15 \mu \mathrm{g} / 0.5 \mathrm{~mL}$ & Egg & No & No & IM§ & No \\
\hline $\begin{array}{l}\text { Flulaval Quadrivalent } \\
\text { (ID Biomedical Corp. } \\
\text { of Quebec) }\end{array}$ & $\begin{array}{l}0.5 \mathrm{~mL} \text { PFS } \\
5.0 \mathrm{~mL} \text { MDV }\end{array}$ & $\geq 6$ mos & $15 \mu \mathrm{g} / 0.5 \mathrm{~mL}$ & Egg & No & No & $I M^{\S}$ & $\begin{array}{c}\text { No } \\
\text { Yes }(<25)\end{array}$ \\
\hline $\begin{array}{l}\text { Fluzone Quadrivalent } \\
\text { (Sanofi Pasteur) }\end{array}$ & $\begin{array}{l}0.25 \mathrm{~mL} \text { PFS } \\
0.5 \mathrm{~mL} \text { PFS } \\
0.5 \mathrm{~mL} \text { SDV } \\
5.0 \mathrm{~mL} \text { MDV }\end{array}$ & $\begin{array}{l}6 \text { through } 35 \mathrm{mos} \\
\geq 3 \mathrm{yrs} \\
\geq 3 \mathrm{yrs} \\
\geq 6 \mathrm{mos}\end{array}$ & $\begin{array}{l}7.5 \mu \mathrm{g} / 0.25 \mathrm{~mL} \\
15 \mu \mathrm{g} / 0.5 \mathrm{~mL}\end{array}$ & Egg & No & No & $I M^{\S}$ & $\begin{array}{c}\text { No } \\
\text { No } \\
\text { No } \\
\text { Yes (25) }\end{array}$ \\
\hline $\begin{array}{l}\text { Flucelvax Quadrivalent } \\
\text { (Seqirus) }\end{array}$ & $\begin{array}{l}0.5 \mathrm{~mL} \text { PFS } \\
5.0 \mathrm{~mL} \text { MDV }\end{array}$ & $\geq 4 \mathrm{yrs}$ & $15 \mu \mathrm{g} / 0.5 \mathrm{~mL}$ & Cell culture & No & No & $\mathrm{IM}^{\S}$ & $\begin{array}{c}\text { No } \\
\text { Yes (25) }\end{array}$ \\
\hline \multicolumn{9}{|c|}{ Trivalent IIV (IIV3)—Standard Dose-Contains inactivated virus } \\
\hline Afluria (Seqirus) & $\begin{array}{l}0.5 \mathrm{~mL} \text { PFS } \\
5.0 \mathrm{~mL} \text { MDV }\end{array}$ & $\begin{array}{l}\geq 5 \text { yrs } \\
\geq 5 \text { yrs (needle/ } \\
\text { syringe) } \\
18 \text { through } 64 \text { yrs } \\
\text { (jet injector) }\end{array}$ & $15 \mu \mathrm{g} / 0.5 \mathrm{~mL}$ & Egg & No & No & $I M^{\S}$ & $\begin{array}{c}\text { No } \\
\text { Yes (24.5) }\end{array}$ \\
\hline \multicolumn{9}{|c|}{ Trivalent IIV3-High-Dose-Contains inactivated virus } \\
\hline $\begin{array}{l}\text { Fluzone High-Dose } \\
\text { (Sanofi Pasteur) }\end{array}$ & $0.5 \mathrm{~mL}$ PFS & $\geq 65 \mathrm{yrs}$ & $60 \mu \mathrm{g} / 0.5 \mathrm{~mL}$ & Egg & No & No & $\mathrm{IM}^{\S}$ & No \\
\hline \multicolumn{9}{|c|}{ Trivalent IIV3—Adjuvanted_Contains inactivated virus } \\
\hline $\begin{array}{l}\text { Quadrivalent RIV (RIV4) } \\
\text { Flublok Quadrivalent } \\
\text { (Sanofi Pasteur) }\end{array}$ & $\begin{array}{l}\text { ntains recombinant } \\
0.5 \mathrm{~mL} \text { PFS }\end{array}$ & $\begin{array}{l}\text { HA } \\
\geq 18 \text { yrs }\end{array}$ & $45 \mu \mathrm{g} / 0.5 \mathrm{~mL}$ & Recombinant & No & No & $I M^{\S}$ & No \\
\hline $\begin{array}{l}\text { Quadrivalent LAIV (LAI } \\
\text { FluMist Quadrivalent } \\
\text { (AstraZeneca) }\end{array}$ & $\begin{array}{l}\text { Contains live, attenu } \\
0.2 \mathrm{~mL} \text { prefilled } \\
\text { single-use } \\
\text { intranasal sprayer }\end{array}$ & $\begin{array}{l}\text { uated, cold-adapted } \\
2 \text { through } 49 \text { yrs }\end{array}$ & $\begin{array}{l}\text { virus } \\
10^{6.5-7.5} \\
\text { fluorescent focus } \\
\text { units } / 0.2 \mathrm{~mL}\end{array}$ & Egg & No & No & NAS & No \\
\hline
\end{tabular}

Abbreviations: ACIP = Advisory Committee on Immunization Practices; HA = hemagglutinin; IIV = inactivated influenza vaccine; IM = intramuscular; LAIV = live attenuated influenza vaccine; $M D V=$ multidose vial; NAS = intranasal; PFS = prefilled syringe; RIV=recombinant influenza vaccine; SDV = single-dose vial.

* Immunization providers should consult Food and Drug Administration-approved prescribing information for 2018-19 influenza vaccines for the most complete and updated information, including (but not limited to) indications, contraindications, warnings, and precautions. Package inserts for U.S.-licensed vaccines are available at https://www.fda.gov/BiologicsBloodVaccines/Vaccines/ApprovedProducts/ucm093833.htm. Availability of specific products and presentations might change and differ from what is described in this table and in the text of this report.

+ Persons with a history of egg allergy may receive any licensed, recommended, age-appropriate influenza vaccine (IIV, RIV4, or LAIV4) that is otherwise appropriate for their health status. Those who report having had reactions to egg involving symptoms other than urticaria (hives), such as angioedema, respiratory distress, lightheadedness, or recurrent emesis; or who required epinephrine or another emergency medical intervention, should be vaccinated in an inpatient or outpatient medical setting (including, but not necessarily limited to, hospitals, clinics, health departments, and physician offices). Vaccine administration should be supervised by a health care provider who is able to recognize and manage severe allergic conditions.

$\S$ For adults and older children, the recommended site for intramuscular influenza vaccination is the deltoid muscle. The preferred site for infants and young children is the anterolateral aspect of the thigh. Specific guidance regarding site and needle length for intramuscular administration is available in the ACIP General Best Practice Guidelines for Immunization, available at https://www.cdc.gov/vaccines/hcp/acip-recs/general-recs/index.html.

seasons' data concerning LAIV effectiveness among children aged 2 through 17 years, including 1) a combined individualpatient-level analysis of data from five U.S. observational studies of LAIV effectiveness for the 2013-14 through 2015-16 seasons, and 2) a systematic review and metaanalysis of U.S. and non-U.S. observational studies of LAIV effectiveness for the 2010-11 through 2016-17 seasons (for which further details are available in the Appendix to the Background Document). These observational data indicated that LAIV was poorly effective against influenza $\mathrm{A}(\mathrm{H} 1 \mathrm{~N} 1)$ pdm09-like viruses, and was significantly less effective than IIV against these viruses. However, LAIV was effective against influenza $B$ viruses, and effectiveness of LAIV and IIV against influenza $\mathrm{A}(\mathrm{H} 3 \mathrm{~N} 2)$ viruses generally did not 
differ significantly. No estimates of the effectiveness of the current formulation of LAIV4, which contains a new H1N1pdm09-like vaccine virus, were available at the time of this review. The third source was manufacturer data concerning shedding and immunogenicity associated with administration of LAIV containing the new H1N1pdm09like vaccine virus, A/Slovenia/2903/2015, among children aged 24 months through $<4$ years. These data suggest that this new H1N1pdm09-like virus has improved replicative fitness over previous $\mathrm{H} 1 \mathrm{~N} 1 \mathrm{pdm}$ 09-like viruses included in LAIV.

3. Regarding recommendations for persons with a history of egg allergy, persons with egg allergy of any severity were previously recommended to receive any licensed, recommended, and age-appropriate influenza vaccine. Use of LAIV4 for persons with egg allergy of any severity was approved by ACIP in February 2016, prior to the recommendations made for the 2016-17 and 2017-18 seasons that LAIV4 not be used in any population because of effectiveness concerns (9). In discussing LAIV4 for egg-allergic persons in February 2016, ACIP heard data from three studies which evaluated the use of LAIV in egg-allergic children, in which no cases of anaphylaxis occurred (10-12).

4. With regard to recommendations for newly licensed influenza vaccines and changes to the licensed indications for existing vaccines, ACIP relies on FDA for review of safety, immunogenicity, and effectiveness data pertaining to the licensure of influenza vaccines. Regulatory information pertinent to the labeling change for Afluria Quadrivalent (IIV4) is available at https://www.fda.gov/ BiologicsBloodVaccines/Vaccines/ApprovedProducts/ ucm 518291.htm. Regulatory information pertinent to the labeling change for Fluarix Quadrivalent (IIV4) is available at https://www.fda.gov/BiologicsBloodVaccines/ Vaccines/ApprovedProducts/ucm342391.htm.

\section{Primary Changes and Updates in the Recommendations}

Routine annual influenza vaccination of all persons aged $\geq 6$ months without contraindications continues to be recommended. No preferential recommendation is made for one influenza vaccine product over another for persons for whom more than one licensed, recommended, and appropriate product is available. Updated information and guidance in this report includes the following:
- Vaccine viruses included in the 2018-19 U.S. trivalent influenza vaccines will be an A/Michigan/45/2015 (H1N1) pdm09-like virus, an A/Singapore/INFIMH-16-0019/2016 (H3N2)-like virus, and a B/Colorado/06/2017-like virus (Victoria lineage). Quadrivalent influenza vaccines will contain these three viruses and an additional influenza $B$ vaccine virus, a B/Phuket/3073/2013-like virus (Yamagata lineage).

- Following two seasons (2016-17 and 2017-18) during which ACIP recommended that LAIV4 not be used, ACIP voted in February 2018 to recommend that for the 2018-19 season, vaccination providers may choose to administer any licensed, age-appropriate influenza vaccine (IIV, RIV4, or LAIV4). LAIV4 is an option for those for whom it is appropriate (Table 2).

- Persons with a history of egg allergy of any severity may receive any licensed, recommended, and age-appropriate influenza vaccine (IIV, RIV4, or LAIV4). IIV and RIV4 have been previously recommended. Use of LAIV4 for persons with egg allergy was approved by ACIP in February 2016. Additional recommendations concerning vaccination of egg-allergic persons are discussed.

- Two recent regulatory actions are described. In August 2017, FDA approved an expanded age indication for Afluria Quadrivalent (IIV4). Previously licensed for ages $\geq 18$ years, Afluria Quadrivalent is now licensed for ages $\geq 5$ years. In January 2018, FDA approved an expanded age indication for Fluarix Quadrivalent (IIV4). Previously licensed for persons aged $\geq 3$ years, Fluarix Quadrivalent is now licensed for persons aged $\geq 6$ months. Children aged 6 through 35 months may receive Fluarix Quadrivalent at the same $0.5 \mathrm{~mL}$ per dose (containing $15 \mu \mathrm{g}$ of hemagglutinin [HA] per vaccine virus) as is used for older children and adults. This licensure creates a third option for inactivated influenza vaccines for children aged 6 through 35 months, in addition to the previously available $0.5 \mathrm{~mL}$ per dose (containing $15 \mu \mathrm{g}$ of HA per vaccine virus) presentation of FluLaval Quadrivalent (IIV4) and $0.25 \mathrm{~mL}$ per dose presentation (containing $7.5 \mu \mathrm{g}$ of HA per vaccine virus) of Fluzone Quadrivalent (IIV4).

\section{Recommendations for the Use of Influenza Vaccines, 2018-19}

\section{Groups Recommended for Vaccination}

Routine annual influenza vaccination is recommended for all persons aged $\geq 6$ months who do not have contraindications. Recommendations regarding timing of vaccination, 
TABLE 2. Contraindications and precautions to the use of influenza vaccines - United States, 2018-19 influenza season*

\begin{tabular}{|c|c|c|}
\hline $\begin{array}{l}\text { Vaccine } \\
\text { type }\end{array}$ & Contraindications & Precautions \\
\hline \multirow[t]{2}{*}{ IIV } & \multirow[t]{2}{*}{$\begin{array}{l}\text { History of severe allergic reaction to any } \\
\text { component of the vaccine }{ }^{\dagger} \text { or after a } \\
\text { previous dose of any influenza vaccine }\end{array}$} & $\begin{array}{l}\text { Moderate or severe acute } \\
\text { illness with or without } \\
\text { fever }\end{array}$ \\
\hline & & $\begin{array}{l}\text { History of Guillain-Barré } \\
\text { syndrome within } 6 \\
\text { weeks of receipt of } \\
\text { influenza vaccine }\end{array}$ \\
\hline \multirow[t]{2}{*}{ RIV } & \multirow[t]{2}{*}{$\begin{array}{l}\text { History of severe allergic reaction to any } \\
\text { component of the vaccine }\end{array}$} & $\begin{array}{l}\text { Moderate or severe acute } \\
\text { illness with or without } \\
\text { fever }\end{array}$ \\
\hline & & $\begin{array}{l}\text { History of Guillain-Barré } \\
\text { syndrome within } \\
6 \text { weeks of receipt of } \\
\text { influenza vaccine }\end{array}$ \\
\hline \multirow[t]{8}{*}{ LAIV } & $\begin{array}{l}\text { History of severe allergic reaction to any } \\
\text { component of the vaccine }{ }^{\dagger} \text { or after a } \\
\text { previous dose of any influenza vaccine }\end{array}$ & $\begin{array}{l}\text { Moderate or severe acute } \\
\text { illness with or without } \\
\text { fever }\end{array}$ \\
\hline & $\begin{array}{l}\text { Concomitant aspirin- or salicylate- } \\
\text { containing therapy in children and } \\
\text { adolescents }\end{array}$ & $\begin{array}{l}\text { History of Guillain-Barré } \\
\text { syndrome within } \\
6 \text { weeks of receipt of } \\
\text { influenza vaccine }\end{array}$ \\
\hline & \multirow{2}{*}{$\begin{array}{l}\text { Children aged } 2 \text { through } 4 \text { years who } \\
\text { have received a diagnosis of asthma or } \\
\text { whose parents or caregivers report that } \\
\text { a health care provider has told them } \\
\text { during the preceding } 12 \text { months that } \\
\text { their child had wheezing or asthma or } \\
\text { whose medical record indicates a } \\
\text { wheezing episode has occurred during } \\
\text { the preceding } 12 \text { months }\end{array}$} & $\begin{array}{l}\text { Asthma in persons aged } \\
\geq 5 \text { years }\end{array}$ \\
\hline & & \multirow{5}{*}{$\begin{array}{l}\text { Other underlying } \\
\text { medical conditions that } \\
\text { might predispose to } \\
\text { complications after } \\
\text { wild-type influenza } \\
\text { infection (e.g., chronic } \\
\text { pulmonary, } \\
\text { cardiovascular [except } \\
\text { isolated hypertension], } \\
\text { renal, hepatic, } \\
\text { neurologic, } \\
\text { hematologic, or } \\
\text { metabolic disorders } \\
\text { [including diabetes } \\
\text { mellitus]) }\end{array}$} \\
\hline & $\begin{array}{l}\text { Children and adults who are } \\
\text { immunocompromised due to any } \\
\text { cause (including immunosuppression } \\
\text { caused by medications or by HIV } \\
\text { infection) }\end{array}$ & \\
\hline & $\begin{array}{l}\text { Close contacts and caregivers of severely } \\
\text { immunosuppressed persons who } \\
\text { require a protected environment }\end{array}$ & \\
\hline & Pregnancy & \\
\hline & $\begin{array}{l}\text { Receipt of influenza antiviral medication } \\
\text { within the previous } 48 \text { hours }\end{array}$ & \\
\hline
\end{tabular}

Abbreviations: ACIP = Advisory Committee on Immunization Practices; IIV = Inactivated Influenza Vaccine; LAIV = Live-Attenuated Influenza Vaccine; RIV = Recombinant Influenza Vaccine.

* Immunization providers should check Food and Drug Administrationapproved prescribing information for 2018-19 influenza vaccines for the most complete and updated information, including (but not limited to) indications, contraindications, and precautions. Package inserts for US-licensed vaccines are available at https://www.fda.gov/BiologicsBloodVaccines/Vaccines/ ApprovedProducts/ucm093833.htm.

${ }^{\dagger}$ History of severe allergic reaction (e.g., anaphylaxis) to egg is a labeled contraindication to the use of IIV and LAIV. However, ACIP recommends that any licensed, recommended, and age-appropriate influenza vaccine (IIV, RIV, or LAIV) may be administered to persons with egg allergy of any severity (see Persons with a History of Egg Allergy for further recommendations and information). considerations for specific populations, the use of specific vaccines, and contraindications and precautions are summarized in the sections that follow.

\section{Timing of Vaccination}

Balancing considerations regarding the unpredictability of timing of onset of the influenza season and concerns that vaccine-induced immunity might wane over the course of a season, it is recommended that vaccination should be offered by the end of October. Children aged 6 months through 8 years who require 2 doses (see Children Aged 6 Months Through 8 Years) should receive their first dose as soon as possible after vaccine becomes available, to allow the second dose (which must be administered $\geq 4$ weeks later) to be received by the end of October. Community vaccination programs should balance maximizing likelihood of persistence of vaccine-induced protection through the season with avoiding missed opportunities to vaccinate or vaccinating after onset of influenza circulation occurs. Revaccination later in the season of persons who have already been fully vaccinated is not recommended. Vaccination should continue to be offered as long as influenza viruses are circulating and unexpired vaccine is available. To avoid missed opportunities for vaccination, providers should offer vaccination during routine health care visits and hospitalizations.

Optimally, vaccination should occur before onset of influenza activity in the community. However, because timing of the onset, peak, and decline of influenza activity varies, the ideal time to start vaccinating cannot be predicted each season. Moreover, more than one outbreak might occur in a given community in a single year. In the United States, localized outbreaks that indicate the start of seasonal influenza activity can occur as early as October. However, in $75 \%$ of influenza

BOX. Abbreviation conventions for vaccines discussed in this report

- IIV = Inactivated Influenza Vaccine

- RIV = Recombinant Influenza Vaccine

- LAIV = Live Attenuated Influenza Vaccine

- Numerals following letter abbreviations indicate valence - 3 for trivalent vaccines

- 4 for quadrivalent vaccines

- Prefixes are used when necessary to refer to some specific vaccine types

- a for adjuvanted vaccine (e.g., aIIV3)

- cc for cell culture-based vaccine (e.g., ccIIV4)

- HD for high-dose vaccine (e.g., HD-IIV3)

- SD for standard-dose vaccine (e.g., SD-IIV3) 
seasons from 1982-83 through 2017-18, peak influenza activity (which often is close to the midpoint of influenza activity for the season) has not occurred until January or later, and in 58\% of seasons, the peak was in February or later (13).

A number of observational studies (14-21) and a post hoc analysis from a randomized controlled trial (22) have reported decreases in vaccine effectiveness (VE) within a single influenza season, with increasing time postvaccination. Waning effects have not been observed consistently across age groups, virus subtypes, and seasons; and observed declines in protection could be at least in part attributable to bias, unmeasured confounding, or the late season emergence of antigenic drift variants that are less well-matched to the vaccine strain. Some studies suggest this occurs to a greater degree with $\mathrm{A}(\mathrm{H} 3 \mathrm{~N} 2)$ viruses than with $\mathrm{A}(\mathrm{H} 1 \mathrm{~N} 1)$ or $\mathrm{B}$ viruses $(19,21)$. This effect might also vary with recipient age; in some studies waning was more pronounced among older adults $(14,15)$ and younger children (15). Rates of decline in VE have also varied. A multiseason (2011-12 through 2014-15) analysis from the U.S. Influenza Vaccine Effectiveness (U.S. Flu VE) Network found that VE declined by about 7\% per month for $\mathrm{H} 3 \mathrm{~N} 2$ and influenza B, and 6\%-11\% per month for H1N1pdm09 (16). $\mathrm{VE}$ remained greater than zero for at least 5 to 6 months after vaccination. An analysis from the 2011-12 through 2013-14 seasons noted protection ranging from $54 \%$ to $67 \%$ during days 0 through 180 postvaccination (20). A third multiseason analysis (2011-12 through 2014-15) conducted in Europe noted a decline in VE to $0 \%$ at 111 days postvaccination for $\mathrm{A}(\mathrm{H} 3 \mathrm{~N} 2)$ viruses. VE against $\mathrm{B}$ viruses declined more slowly and $\mathrm{VE}$ against $\mathrm{A}(\mathrm{H} 1 \mathrm{~N} 1)$ viruses remained roughly stable at $50-55 \%$ through the influenza season $(21)$.

Variable data concerning presence and rate of waning immunity following influenza vaccination, coupled with the unpredictable timing of the influenza season each year, prevent determination of an optimal time to vaccinate. Programmatic issues are also a consideration. Although some available data indicate that early vaccination (e.g., in July and August) might be associated with suboptimal immunity before the end of the influenza season, particularly among older adults, the relative contribution of potential waning of immunity compared with those of other determinants of the impact of vaccination (e.g., timing and severity of the influenza season, the impact of missed opportunities when individuals delay vaccination and fail to return later in the season, and programmatic constraints) is unknown. Although delaying vaccination might result in greater immunity later in the season, deferral also might result in missed opportunities to vaccinate, as well as difficulties in vaccinating a population within a more constrained time period. Efforts should be structured to optimize vaccination coverage before influenza activity in the community begins.
Vaccination efforts should continue throughout the season because the duration of the influenza season varies, and influenza activity might not occur in certain communities until February or March. Providers should offer influenza vaccine routinely, and organized vaccination campaigns should continue throughout the influenza season, including after influenza activity has begun in the community. Although vaccination by the end of October is recommended, vaccine administered in December or later, even if influenza activity has already begun, is likely to be beneficial in the majority of influenza seasons.

\section{Guidance for Use in Specific Populations and Situations}

\section{Populations at Higher Risk for Medical Complications Attributable to Severe Influenza}

All persons aged $\geq 6$ months without contraindications should be vaccinated annually. However, vaccination to prevent influenza is particularly important for persons who are at increased risk for severe complications from influenza and for influenza-related outpatient, emergency department, or hospital visits. When vaccine supply is limited, vaccination efforts should focus on delivering vaccination to persons at higher risk for medical complications attributable to severe influenza who do not have contraindications. These persons include (no hierarchy is implied by order of listing):

- All children aged 6 through 59 months;

- All persons aged $\geq 50$ years;

- Adults and children who have chronic pulmonary (including asthma) or cardiovascular (excluding isolated hypertension), renal, hepatic, neurologic, hematologic, or metabolic disorders (including diabetes mellitus);

- Persons who are immunocompromised due to any cause (including immunosuppression caused by medications or by HIV infection);

- Women who are or will be pregnant during the influenza season;

- Children and adolescents (aged 6 months through 18 years) who are receiving aspirin- or salicylate-containing medications and who might be at risk for experiencing Reye syndrome after influenza virus infection;

- Residents of nursing homes and other long-term care facilities;

- American Indians/Alaska Natives; and

- Persons who are extremely obese (body mass index $\geq 40$ ).

An age-appropriate IIV or RIV4 is suitable for persons in all risk groups. LAIV4 is not recommended for some populations, including some groups listed above. Contraindications and precautions to the use of LAIV4 are noted (Table 2). 


\section{Persons Who Live with or Care for Persons at Higher Risk for Influenza-Related Complications}

All persons aged $\geq 6$ months without contraindications should be vaccinated annually; however, continued emphasis should be placed on vaccination of persons who live with or care for persons at higher risk for influenza-related complications. When vaccine supply is limited, vaccination efforts should focus on delivering vaccination to persons at higher risk for influenza-related complications, as well as persons who live with or care for such persons:

- Health care personnel, including physicians, nurses, and other workers in inpatient and outpatient-care settings, medical emergency-response workers (e.g., paramedics and emergency medical technicians), employees of nursing home and long-term care facilities who have contact with patients or residents, and students in these professions who will have contact with patients. ACIP guidance for immunization of health care personnel has been published previously (23);

- Household contacts (including children) and caregivers of children aged $\leq 59$ months (i.e., aged $<5$ years) and adults aged $\geq 50$ years, particularly contacts of children aged $<6$ months; and

- Household contacts (including children) and caregivers of persons with medical conditions that put them at higher risk for severe complications from influenza.

Health care personnel and persons who are contacts of persons in these groups (with the exception of those of severely immunocompromised persons who require a protected environment) may receive any influenza vaccine that is otherwise indicated. Persons who care for severely immunocompromised persons requiring a protected environment should receive either IIV or RIV4. ACIP and the Healthcare Infection Control Practices Advisory Committee (HICPAC) have previously recommended that health care personnel who receive LAIV should avoid providing care for severely immunosuppressed patients requiring a protected environment for 7 days after vaccination, and that hospital visitors who have received LAIV should avoid contact with such persons for 7 days after vaccination (24). However, such persons need not be restricted from visiting less severely immunosuppressed patients.

\section{Children Aged 6 Months Through 8 Years}

Dose volume for children aged 6 through 35 months: Children aged 6 through 35 months may receive one of three IIV4 products at the appropriate volume for each dose needed. The appropriate dose volume varies by product:

- $0.5 \mathrm{~mL}$ FluLaval Quadrivalent (containing $15 \mu \mathrm{g}$ of HA per vaccine virus),
- $0.5 \mathrm{~mL}$ Fluarix Quadrivalent (containing $15 \mu \mathrm{g}$ of HA per vaccine virus), or

- $0.25 \mathrm{~mL}$ Fluzone Quadrivalent (containing $7.5 \mu \mathrm{g}$ of HA per vaccine virus).

Alternatively, healthy children aged $\geq 2$ years may receive LAIV4, $0.2 \mathrm{~mL}$ intranasally $(0.1 \mathrm{~mL}$ each nostril) (see Contraindications and Precautions for the Use of LAIV4; Table 2).

Care should be taken to administer the appropriate volume for each needed dose of the respective product. In each instance the needed volume may be administered from a prefilled syringe containing the appropriate volume (as supplied by the manufacturer), a single dose vial, or a multidose vial. However, if a $0.5 \mathrm{~mL}$ single-dose vial of Fluzone Quadrivalent is used for a child aged 6 through 35 months, only half the volume should be administered and the other half should be discarded.

Before November 2016, the only IIV formulations licensed for children aged 6 through 35 months were the $0.25 \mathrm{~mL}$ dose formulations of Fluzone and Fluzone Quadrivalent (containing $7.5 \mu \mathrm{g}$ of HA per vaccine virus). The recommendation for use of a reduced dose volume for children in this age group (half that recommended for persons aged $\geq 3$ years) was based on increased reactogenicity noted among children (particularly younger children) following influenza vaccines, primarily observed with whole-virus inactivated vaccines (25-29). Vaccines more similar to currently available splitvirus inactivated products demonstrated less reactogenicity (29). In a randomized trial comparing immunogenicity and safety of $0.5 \mathrm{~mL}$ FluLaval Quadrivalent with $0.25 \mathrm{~mL}$ Fluzone Quadrivalent, safety and reactogenicity were similar between the two vaccines (30). In a post hoc analysis, superior immunogenicity was noted for the B components of FluLaval Quadrivalent among infants aged 6 through 17 months and for unprimed children (those who had not previously received at least 2 doses of influenza vaccine) aged 6 through 35 months.

Number of doses for children aged 6 months through 8 years: Evidence from several studies indicates that children aged 6 months through 8 years require 2 doses of influenza vaccine administered a minimum of 4 weeks apart during their first season of vaccination for optimal protection (31-34). Children aged 6 months through 8 years who have previously received $\geq 2$ total doses of trivalent or quadrivalent influenza vaccine at least 4 weeks apart before July 1, 2018, require only one dose for 2018-19. The 2 doses of influenza vaccine do not have to have been administered in the same season or consecutive seasons. Children in this age group who have not previously received $\geq 2$ doses of trivalent or quadrivalent influenza vaccine before July 1, 2018 require 2 doses for the 2018-19 season. The interval between the 2 doses should be at least 4 weeks (Figure). 
FIGURE. Influenza vaccine dosing algorithm for children aged 6 months through 8 years - Advisory Committee on Immunization Practices, United States, 2018-19 influenza season

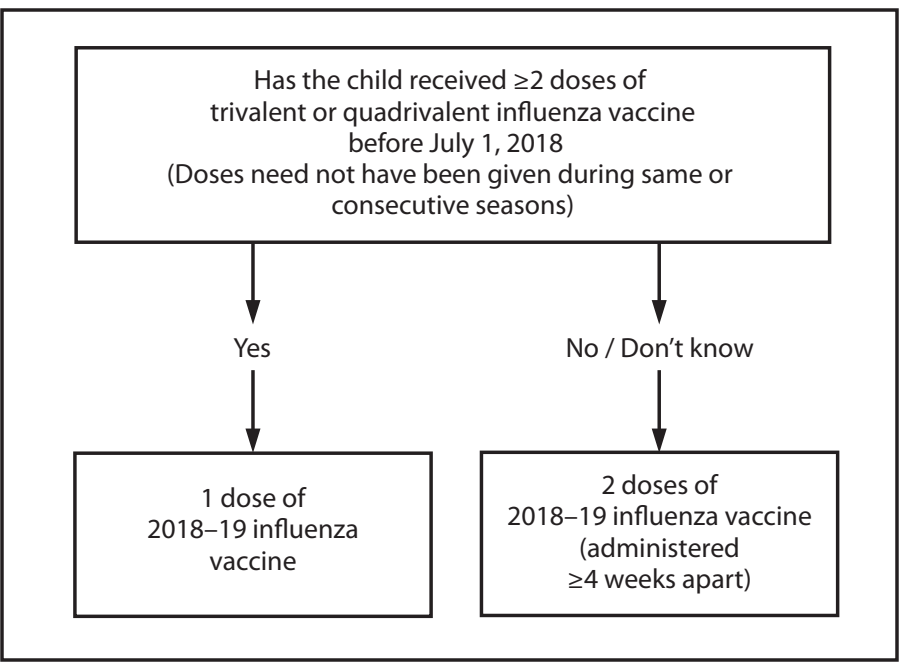

\section{Pregnant Women}

Pregnant and postpartum women have been observed to be at higher risk for severe illness and complications from influenza, particularly during the second and third trimesters. ACIP and the American College of Obstetricians and Gynecologists (35-37) recommend that all women who are pregnant or who might be pregnant during the influenza season receive influenza vaccine. Any licensed, recommended, and age-appropriate IIV or RIV4 may be used. LAIV4 should not be used during pregnancy. Influenza vaccine can be administered at any time during pregnancy, before and during the influenza season.

Although there is substantial experience with the use of IIVs during pregnancy, data specifically reflecting administration of influenza vaccines during the first trimester are relatively limited (see Safety of Influenza Vaccines-Pregnant Women and Neonates in the Background Document). Most studies have not noted an association between influenza vaccination and adverse pregnancy outcomes. One recent observational Vaccine Safety Datalink (VSD) study conducted during the 2010-11 and 2011-12 seasons noted an association between receipt of IIV containing H1N1pdm09 and risk for spontaneous abortion (miscarriage) in the 28 days after IIV, when an H1N1pdm-09-containing vaccine had also been received the previous season (38). This was an unexpected finding, as prior studies (39-47), and systematic reviews $(48,49)$, did not find an association between IIV and spontaneous abortion. A follow-up VSD study is in progress (50).

There is substantially less experience with more recently licensed IIV products (e.g., quadrivalent, cell culture-based, and adjuvanted vaccines) during pregnancy as compared with previously available products. For RIV (available as RIV3 from 2013-14 through 2017-18, and as RIV4 since 2017-18), data are limited to reports of pregnancies occurring incidentally during clinical trials, VAERS reports, and pregnancy registry reports. Pregnancy registries and surveillance studies exist for some products; information may be found in package inserts (51-56), available at https://www. fda.gov/BiologicsBloodVaccines/Vaccines/ApprovedProducts/ ucm094045.htm for trivalent vaccines and https://www.fda. gov/BiologicsBloodVaccines/Vaccines/ApprovedProducts/ ucm 295057.htm for quadrivalent vaccines.

\section{Older Adults}

Because of the vulnerability of this population to severe influenza illness, hospitalization, and death, efficacy and effectiveness of influenza vaccines among older adults is an area of active research (see Immunogenicity, Efficacy, and Effectiveness of Influenza Vaccines: HD-IIV3, aIIV3, and RIV4 for Older Adults in the Background Document). Recent comparative studies of vaccine efficacy/effectiveness against laboratory-confirmed influenza outcomes among older adults have focused on HD-IIV3 (Fluzone High-Dose) $(57,58$ ), RIV4 (Flublok Quadrivalent) (59), and aIIV3 (Fluad) (60) (see Table in Background Document; https://www.cdc.gov/ flu/professionals/acip/2018-19/table3.html). Of note, each of these three vaccines has been studied in comparison to a standard dose, unadjuvanted IIV (SD-IIV3 as the comparator for HD-IIV3 and aIIV3; SD-IIV4 as the comparator for RIV4). To date, HD-IIV3 has been the most extensively studied in this regard, and evidence has accumulated for its superior efficacy and effectiveness compared with SD-IIV3 in this population. Data from studies comparing the efficacy or effectiveness of HD-IIV3, aIIV3, and RIV4 with one another against laboratoryconfirmed influenza outcomes among older adults are limited, which prevents recommending one of these three vaccines over another for this population. In comparative safety studies, some injection site and systemic reactions were observed more frequently in older persons vaccinated with HD-IIV3 and aIIV3, compared with unadjuvanted SD-IIV3 $(61,62)$.

Fluzone High-Dose (HD-IIV3) met prespecified criteria for superior efficacy against laboratory-confirmed influenza to that of SD-IIV3 in a randomized trial conducted over two seasons among 31,989 persons aged $\geq 65$ years, and might provide better protection than SD-IIV3 for this age group $(57,63,64)$. For the primary outcome (prevention of laboratory-confirmed influenza caused by any viral type or subtype and associated with protocol-defined ILI), relative efficacy of HD-IIV3 compared with SD-IIV3 was 24.2\% $(95 \% \mathrm{CI}=9.7-36.5 \%)$. These findings are further supported by results from retrospective studies of Centers for Medicare and Medicaid Services (CMS) and Veterans Administration 
data, as well as a cluster-randomized trial of HD-IIV3 versus SD-IIV among older adults in nursing homes (65-69). A metaanalysis reported that $\mathrm{HD}-\mathrm{IIV} 3$ provided better protection than SD-IIV3 against ILI (relative VE $=19.5 \%$; 95\% CI $=8.6-$ 29.0\%); all-cause hospitalizations (relative $\mathrm{VE}=9.1 \%$; $95 \%$ $\mathrm{CI}=2.4-15.3$ ); and hospitalizations due to influenza (relative $\mathrm{VE}=17.8 \% ; 95 \% \mathrm{CI}=8.1-26.5$ ), pneumonia (relative $\mathrm{VE}=24.3 \% ; 95 \% \mathrm{CI}=13.9-33.4)$, and cardiorespiratory events (relative VE $=18.2 \%$; 95\% CI $=6.8-28.1)(70)$.

In an exploratory analysis of data from a single-season randomized trial conducted among 8,604 adults aged $\geq 50$ years, Flublok Quadrivalent (RIV4) was more efficacious than SD-IIV4 (59,71); however, no claim of superiority was approved for the package insert (71). For the primary outcome (RT-PCR-confirmed, protocol-defined ILI caused by any influenza virus type or subtype), the relative VE of RIV4 compared with IIV4 was 30\% (95\% CI $=10-47)$. When restricted to persons aged $\geq 65$ years, the relative VE of RIV4 was $17 \%(95 \% \mathrm{CI}=-20-43 \%)$.

Fluad (aIIV3) was more effective against laboratory-confirmed influenza than unadjuvanted SD-IIV3 among adults aged $\geq 65$ years ( $\mathrm{N}=227 ; 165$ of whom received aIIV3 and 62 IIV3) in an analysis from a small single-season observational study $(60)$. Relative effectiveness of aIIV3 compared with unadjuvanted IIV3 was 63\% (95\% CI = 4-86). No data are yet available concerning efficacy of aIIV3 compared with nonadjuvanted IIV3 against laboratory-confirmed influenza outcomes from a randomized trial in this population.

Additional data concerning these vaccines from studies examining immunogenicity and nonlaboratory-confirmed influenza outcomes are discussed in the Background Document. ACIP will continue to review data concerning the efficacy and effectiveness of these vaccines as more information emerges. No preference is expressed for any one vaccine type. Vaccination should not be delayed if a specific product is not readily available. For persons aged $\geq 65$ years, any age-appropriate IIV formulation (standard-dose or highdose, trivalent or quadrivalent, unadjuvanted or adjuvanted) or RIV4 are acceptable options.

\section{Immunocompromised Persons}

Immunocompromised states comprise a heterogeneous range of conditions. In many instances, limited data are available regarding the use of influenza vaccines in the setting of specific immunocompromised states. ACIP recommends that LAIV4 not be used for immunocompromised persons (72) because of the uncertain but biologically plausible risk for disease attributable to the vaccine virus. In addition to potential safety issues, immune response to live or inactivated vaccines might be blunted in some clinical situations, such as for persons with congenital immune deficiencies, persons receiving cancer chemotherapy, and persons receiving immunosuppressive medications. For this reason, timing of vaccination might be a consideration (e.g., vaccinating during some period either before or after an immunocompromising intervention).

The Infectious Diseases Society of America (IDSA) has published detailed guidance for the selection and timing of vaccines for persons with specific immunocompromising conditions, including congenital immune disorders, stem cell and solid organ transplant, anatomic and functional asplenia, and therapeutic drug-induced immunosuppression, as well as for persons with cochlear implants or other conditions leading to persistent cerebrospinal fluid-oropharyngeal communication (73). Given the paucity of safety data for LAIV in most of these populations, and the availability of alternative vaccines, IIV or RIV4 should be used instead of LAIV for these persons. ACIP will continue to review accumulating data on use of influenza vaccines in these contexts.

\section{Persons with a History of Guillain-Barré Syndrome Following Influenza Vaccination}

A history of Guillain-Barré Syndrome (GBS) within 6 weeks following a previous dose of any type of influenza vaccine is considered a precaution to vaccination (Table 2). Persons who are not at higher risk for severe influenza complications (see Populations at Higher Risk for Medical Complications Attributable to Severe Influenza) and who are known to have experienced GBS within 6 weeks of a previous influenza vaccination generally should not be vaccinated. As an alternative to vaccination, physicians might consider using influenza antiviral chemoprophylaxis for these persons (74). However, the benefits of influenza vaccination might outweigh the risks for certain persons who have a history of GBS and who also are at higher risk for severe complications from influenza.

\section{Persons with a History of Egg Allergy}

As is the case for other vaccines, influenza vaccines contain various different components that might cause allergic and anaphylactic reactions. Not all such reactions are related to egg proteins; however, the possibility of reactions to influenza vaccines in egg-allergic persons might be of concern to these persons and vaccine providers. Currently available influenza vaccines, with the exceptions of RIV4 (Flublok Quadrivalent) and ccIIV4 (Flucelvax Quadrivalent), are prepared by propagation of virus in embryonated eggs. Only RIV4 is considered egg-free. For ccIIV4, ovalbumin is not directly measured. During manufacture of ccIIV4, viruses are propagated in mammalian cells rather than in eggs. However, one of the four viruses provided to the manufacturer is eggderived; therefore, egg proteins might potentially be introduced 
at the start of the manufacturing process. Once these viruses are received by the manufacturer, no eggs are used, and dilutions at various steps during the manufacturing process result in a theoretical maximum of $1.7 \times 10^{-8} \mu \mathrm{g} / 0.5 \mathrm{~mL}$ dose of total egg protein (Seqirus, unpublished data, 2018).

Severe allergic reactions to vaccines, although rare, can occur at any time, even in the absence of a history of previous allergic reaction. Therefore, all vaccine providers should be familiar with the office emergency plan, and be certified in cardiopulmonary resuscitation (72). For persons who report a history of egg allergy, ACIP recommends the following (based upon the recipient's previous symptoms after exposure to egg):

- Persons with a history of egg allergy who have experienced only urticaria (hives) after exposure to egg should receive influenza vaccine. Any licensed, recommended, and ageappropriate influenza vaccine (i.e., any IIV, RIV4, or LAIV4) that is otherwise appropriate for the recipient's health status may be used.

- Persons who report having had reactions to egg involving symptoms other than urticaria (hives), such as angioedema, respiratory distress, lightheadedness, or recurrent emesis; or who required epinephrine or another emergency medical intervention, may similarly receive any licensed, recommended, and age-appropriate influenza vaccine (i.e., any IIV, RIV4, or LAIV4) that is otherwise appropriate for their health status. The selected vaccine should be administered in an inpatient or outpatient medical setting (including, but not necessarily limited to, hospitals, clinics, health departments, and physician offices). Vaccine administration should be supervised by a health care provider who is able to recognize and manage severe allergic reactions.

- A previous severe allergic reaction to influenza vaccine, regardless of the component suspected of being responsible for the reaction, is a contraindication to future receipt of the vaccine.

No postvaccination observation period is recommended specifically for egg-allergic persons. However, ACIP recommends that vaccine providers consider observing patients (seated or supine) for 15 minutes following administration of any vaccine to decrease the risk for injury should syncope occur (72).

Persons who are able to eat lightly cooked egg (e.g., scrambled egg) without reaction are unlikely to be allergic. Egg-allergic persons might tolerate egg in baked products (e.g., bread or cake). Tolerance to egg-containing foods does not exclude the possibility of egg allergy. Egg allergy can be confirmed by a consistent medical history of adverse reactions to eggs and egg-containing foods, plus skin and/or blood testing for immunoglobulin E directed against egg proteins (75).
Occasional cases of anaphylaxis in egg-allergic persons have been reported to VAERS after administration of influenza vaccines $(76,77)$. ACIP will continue to review available data regarding anaphylaxis cases following influenza vaccines.

\section{Vaccination Issues for Travelers}

Travelers who want to reduce the risk for influenza infection should consider influenza vaccination, preferably at least 2 weeks before departure. In particular, persons residing in the United States who are at higher risk for complications of influenza and who were not vaccinated with influenza vaccine during the preceding Northern Hemisphere fall or winter should consider receiving influenza vaccine before departure if they plan to travel to the tropics, with organized tourist groups or on cruise ships, or to the Southern Hemisphere during the Southern Hemisphere influenza season (April-September).

Persons at higher risk who received the previous season's vaccine before travel should consult with their health care provider to discuss the risk for influenza or other travel-related diseases before embarking on travel during the summer. Persons vaccinated before travel should receive the current vaccine the following fall or winter.

In temperate climate regions of the Northern and Southern hemispheres, influenza activity is seasonal, occurring approximately from October through May in the Northern Hemisphere and April through September in the Southern Hemisphere. In the tropics, influenza occurs throughout the year. Travelers can be exposed to influenza when travelling to an area where influenza is circulating, or when traveling as part of large tourist groups (e.g., on cruise ships) that include persons from areas of the world in which influenza viruses are circulating (78-81).

Influenza vaccine formulated for the Southern Hemisphere might differ in viral composition from the Northern Hemisphere vaccine. For persons traveling to the Southern Hemisphere during the Southern Hemisphere influenza season, receipt of a current U.S.-licensed Southern Hemisphere formulation influenza vaccine prior to departure might be reasonable, but might not be feasible in many instances. With the exception of the Southern Hemisphere formulation of Fluzone Quadrivalent (IIV4), Southern Hemisphere formulation seasonal influenza vaccines are not licensed in the U.S., and Southern Hemisphere formulations generally are not commercially available in the United States. More information on influenza vaccines and travel is available at https://www. cdc.gov/flu/travelers/travelersfacts.htm.

\section{Use of Influenza Antiviral Medications}

Administration of IIV or RIV4 to persons receiving influenza antiviral medications for treatment or chemoprophylaxis is acceptable. However, influenza antiviral medications may 
reduce the effectiveness of LAIV4 if given within 48 hours before to 14 days after LAIV4 (82). Persons who receive influenza antiviral medications during this period surrounding receipt of LAIV 4 may be revaccinated with another appropriate vaccine formulation (e.g., IIV or RIV4).

\section{Administration of Influenza Vaccines with Other Vaccines}

In general, data regarding simultaneous or sequential administration for the many potential combinations of vaccines are limited. Therefore, following the ACIP General Best Practice Guidelines for Immunization is prudent (72). IIVs and RIV4 may be administered concomitantly or sequentially with other inactivated vaccines or with live vaccines. Injectable vaccines that are given concomitantly should be administered at separate anatomical sites. LAIV4 may be administered simultaneously with other live or inactivated vaccines. However, following administration of a live vaccine (such as LAIV4), at least 4 weeks should pass before another live vaccine is administered.

Relatively limited data are available on the concomitant administration of influenza vaccines with other vaccines. In a study comparing the immunogenicity of IIV and live attenuated zoster vaccine given either concomitantly or separated by a 4 -week interval to adults aged $\geq 50$ years, antibody responses were similar for both schedules (83). In some studies, reduced responses have been noted to PCV13 $(84,85)$, tetanus antigens $(86)$, and pertussis antigens (86) when co-administered with IIV; in most instances the clinical significance of this is uncertain. Reassuring safety profiles have been noted for simultaneous administration of IIV with live attenuated zoster vaccine (83), PCV13 (84,85), PPSV23 (87) and Tdap (86) among adults and of Tdap among pregnant women (88). Increased prevalence of injection site and/or systemic adverse reactions has been noted with concurrent administration in some of these studies, but these symptoms have generally been reported to be mild or moderate.

Among children, co-administration of IIV and PCV13 was associated with increased risk for fever on the day of vaccination and the day following (i.e., days $0-1$ postvaccination) in children aged 6 through 23 months in a study conducted during the 2011-12 season (89). Increased risk for febrile seizures in this age group has been noted within days 0-1 following co-administration of IIV with PCV7, PCV13, or DTaP-containing vaccines during the 2006-07 through 2010-11 seasons (90), and with PCV13 during the 2014-15 season (91). While frightening to parents, most febrile seizures are brief and have a good prognosis (92). After considering risks and benefits, no changes in the recommendations for administration of these vaccines were made, and these vaccines may be given concomitantly. Surveillance of febrile seizures is ongoing through VAERS, and the VSD annual influenza vaccine safety surveillance includes monitoring for seizures following vaccination.

Studies of concomitant administration of LAIV with other vaccines are limited. Concurrent administration to children of LAIV3 with MMR and varicella vaccine was not associated with diminished immunogenicity to antigens in any of the vaccines in one study (93); diminished response to rubella was observed in another study examining co-administration of LAIV3 and MMR (94). No safety concerns were revealed in these studies.

In recent years several vaccines containing novel, nonaluminum adjuvants have been licensed for use in the United States. These include $\mathrm{ASO}_{\mathrm{B}}$ (in Shingrix, recombinant zoster subunit vaccine); MF59 (in Fluad, aIIV3); and cytosine phosphoguanine oligodeoxynucleotide (in Heplisav-B, recombinant hepatitis $B$ surface antigen vaccine). Data are limited regarding co-administration of these vaccines with other adjuvanted or unadjuvanted vaccines. Co-administration of Shingrix with unadjuvanted IIV4 has been studied; no evidence of decreased immunogenicity or safety concerns were noted (95). The immunogenicity and safety of simultaneous or sequential administration of two novel adjuvant-containing vaccines has not been evaluated, and the ideal interval between such vaccines when given sequentially is not known. In the study of Shingrix and IIV4 discussed above, most reactogenicity symptoms resolved within 4 days. Given unknown but theoretical concerns of increased reactogenicity when administering two novel adjuvant-containing vaccines, and the availability of nonadjuvanted influenza vaccine options, selection of a nonadjuvanted influenza vaccine may be considered in situations where influenza vaccine and another vaccine containing a novel adjuvant are to be administered concomitantly. However, vaccination should not be delayed if a specific product is not available. Vaccines with newer adjuvants, like other vaccines, should be administered at separate sites from other vaccines that are given concomitantly (72).

\section{Influenza Vaccine Composition and Available Products \\ Influenza Vaccine Composition for the 2018-19 Season}

All influenza vaccines licensed in the United States will contain components derived from influenza viruses antigenically similar to those recommended by FDA (https://www.fda.gov/downloads/AdvisoryCommittees/ CommitteesMeetingMaterials/BloodVaccinesandOtherBiologics/ VaccinesandRelatedBiologicalProductsAdvisoryCommittee/ 
UCM602610.pdf). Both trivalent and quadrivalent influenza vaccines will be available in the United States. The 2018-19 U.S. influenza vaccines will contain hemagglutinin derived from the following:

- an A/Michigan/45/2015 (H1N1)pdm09-like virus,

- an A/Singapore/INFIMH-16-0019/2016 (H3N2)-like virus, and

- a B/Colorado/06/2017-like virus (Victoria lineage).

The 2018-19 U.S. quadrivalent vaccines will contain the same three antigens and an additional influenza $\mathrm{B}$ virus component, a B/Phuket/3073/2013-like virus (Yamagata lineage). Compared with the 2017-18 season, the composition for 2018-19 represents changes in the $\mathrm{A}(\mathrm{H} 3 \mathrm{~N} 2)$ and B (Victoria) components of both the trivalent and quadrivalent vaccines.

\section{Vaccine Products for the 2018-19 Season}

A variety of influenza vaccine products are licensed and available from several different manufacturers (Table 1). For many vaccine recipients, more than one type or brand of vaccine might be appropriate within approved indications and ACIP recommendations. A licensed, age-appropriate influenza vaccine product should be used. Not all products are likely to be uniformly available in any practice setting or locality. Vaccination should not be delayed in order to obtain a specific product when an appropriate one is already available. Within these guidelines and approved indications, where more than one type of vaccine is appropriate and available, no preferential recommendation is made for use of any influenza vaccine product over another.

Since the publication of the previous season's guidelines, there have been changes in the licensed age indications for Afluria Quadrivalent and Fluarix Quadrivalent. Further details are in the Recent Influenza Vaccine Product Approvals section. New licensures and changes to FDA-approved labeling might occur subsequent to publication of this report. As these changes occur, they will be reflected in the online version of Table 1, available at https://www.cdc.gov/flu/protect/vaccine/vaccines.htm.

\section{Dosage, Administration, Contraindications, and Precautions}

\section{Inactivated Influenza Vaccines (IIVs)}

Available products: IIVs comprise multiple products (Table 1). Both quadrivalent and trivalent formulations are available. For the 2018-19 season, it is anticipated that all standard-dose, unadjuvanted inactivated influenza vaccines will be quadrivalent (IIV4s), with the exception of Afluria, which will be available in both trivalent (IIV3) and quadrivalent formulations. High-dose unadjuvanted inactivated influenza vaccine (HD-IIV3, Fluzone High-Dose) and adjuvanted inactivated influenza vaccine (aIIV3, Fluad) will be trivalent.

With one exception, U.S.-licensed IIVs are manufactured through propagation of virus in eggs. The exception, the cell culture-based vaccine Flucelvax Quadrivalent (ccIIV4), contains vaccine viruses propagated in Madin-Darby canine kidney cells. Flucelvax Quadrivalent is not considered egg-free, as one of the initial vaccine viruses provided to the manufacturer is eggderived. For the 2018-19 season, the influenza A (H3N2) and both influenza $\mathrm{B}$ components will be cell-derived; the influenza $\mathrm{A}$ (H1N1) component will be egg-derived.

With one exception, IIVs licensed in the United States contain no adjuvant. The exception, Fluad (aIIV3) contains the adjuvant MF59.

There are IIVs that are licensed for persons as young as 6 months of age. However, age indications for the various individual IIVs differ (Table 1). Only age-appropriate products should be administered. Providers should consult package inserts and updated CDC/ACIP guidance for current information.

Dosage and administration: All IIV preparations available for the 2018-19 season contain $15 \mu \mathrm{g}$ of HA per vaccine virus strain ( $45 \mu \mathrm{g}$ total for IIV3s and $60 \mu \mathrm{g}$ total for IIV4s) per $0.5 \mathrm{~mL}$ dose, with the exception of Fluzone High-Dose. Fluzone High-Dose (HD-IIV3), an IIV3 licensed for persons aged $\geq 65$ years, contains $60 \mu \mathrm{g}$ of HA per vaccine virus strain (180 $\mathrm{g}$ total) (63).

For children aged 6 through 35 months, three IIV4 products are licensed by FDA. The approved dose volumes differ for these products. For each recommended dose, children in this age group may receive either 1) $0.5 \mathrm{~mL}$ of FluLaval Quadrivalent (51), which contains $15 \mu \mathrm{g}$ of HA per virus; 2) $0.5 \mathrm{~mL}$ of Fluarix Quadrivalent (52), which contains $15 \mu \mathrm{g}$ of HA per virus; or 3) $0.25 \mathrm{~mL}$ of Fluzone Quadrivalent (56), which contains $7.5 \mu \mathrm{g}$ of HA per virus. Care must be taken to administer each at the appropriate dose for each product in this age group. If prefilled syringes are not available, the dose can be taken from a single-use or multidose vial, at the appropriate volume for the given product.

Children aged 36 months through 17 years and adults aged $\geq 18$ years who are receiving IIV should receive $0.5 \mathrm{~mL}$ per dose. If a smaller intramuscular vaccine dose (e.g., $0.25 \mathrm{~mL}$ ) is administered inadvertently to a person aged $\geq 36$ months, an additional $0.25 \mathrm{~mL}$ dose should be administered to provide a full dose $(0.5 \mathrm{~mL})$. If the error is discovered later (after the patient has left the vaccination setting), a full $0.5 \mathrm{~mL}$ dose should be administered as soon as the patient can return. Vaccination with a formulation approved for adult use should be counted as a dose if inadvertently administered to a child.

IIVs are administered intramuscularly. For adults and older children, the deltoid is the preferred site. Infants and younger children should be vaccinated in the anterolateral thigh. 
Additional specific guidance regarding site selection and needle length for intramuscular administration is provided in the ACIP General Best Practice Guidelines for Immunization (72). Two IIVs, Afluria (IIV3) and Afluria Quadrivalent (IIV4), are licensed for intramuscular administration via jet injector (Stratis, Pharmajet) for persons aged 18 through 64 years $(53,96)$.

Trivalent versus quadrivalent IIVs: Both trivalent and quadrivalent IIVs will be available during the 2018-19 season. Quadrivalent vaccines contain one virus from each of the two influenza $\mathrm{B}$ lineages (one B/Victoria virus and one B/Yamagata virus), whereas trivalent vaccines contain one influenza $B$ virus from one lineage. Quadrivalent vaccines are thus designed to provide broader protection against circulating influenza $B$ viruses. However, no preference is expressed for either IIV3 or IIV4.

Contraindications and precautions for the use of IIVs: Manufacturer package inserts and updated CDC/ACIP guidance should be consulted for current information on contraindications and precautions for individual vaccine products. In general, history of severe allergic reaction to the vaccine or any of its components (including egg) is a labeled contraindication to the receipt of IIVs (Table 2). However, ACIP makes specific recommendations for the use of influenza vaccine for persons with egg allergy (see Persons with a History of Egg Allergy). Influenza vaccine is not recommended for persons with a history of severe allergic reaction to the vaccine or to components other than egg. Information about vaccine components is located in package inserts from each manufacturer. Prophylactic use of antiviral agents is an option for preventing influenza among persons who cannot receive vaccine (74).

Moderate or severe acute illness with or without fever is a general precaution for vaccination (72). GBS within 6 weeks following a previous dose of influenza vaccine is considered a precaution for use of influenza vaccines (Table 2).

\section{Recombinant Influenza Vaccine (RIV4)}

Available products: One RIV product, Flublok Quadrivalent (RIV4), is expected to be available for the 2018-19 influenza season. RIV4 is indicated for persons aged $\geq 18$ years. RIV4 is manufactured without the use of influenza viruses; therefore, similarly to IIVs, no shedding of vaccine virus will occur. RIV4 is produced without the use of eggs, and is egg-free. No preference is expressed for RIV4 versus IIVs within specified indications.

Dosage and administration: RIV4 is administered by intramuscular injection. A $0.5 \mathrm{~mL}$ dose contains $45 \mu \mathrm{g}$ of HA derived from each vaccine virus (180 $\mu \mathrm{g}$ total) (55).

Contraindications and precautions for the use of RIV4: RIV4 is contraindicated in persons who have had a severe allergic reaction to any component of the vaccine. Moderate or severe acute illness with or without fever is a general precaution for vaccination (72). GBS within 6 weeks following a previous dose of influenza vaccine is considered a precaution for use of influenza vaccines (Table 2). RIV4 is not licensed for use in children aged $<18$ years.

\section{Live Attenuated Influenza Vaccine (LAIV4)}

Available products: One LAIV4 product, FluMist Quadrivalent, is expected to be available during the 2018-19 influenza season. LAIV4 is licensed for persons aged 2 through 49 years.

Dosage and administration: LAIV4 is administered intranasally using the supplied prefilled, single-use sprayer containing $0.2 \mathrm{~mL}$ of vaccine. Approximately $0.1 \mathrm{~mL}$ (i.e., half of the total sprayer contents) is sprayed into the first nostril while the recipient is in the upright position. An attached dose-divider clip is removed from the sprayer to administer the second half of the dose into the other nostril. If the vaccine recipient sneezes immediately after administration, the dose should not be repeated. However, if nasal congestion is present that might impede delivery of the vaccine to the nasopharyngeal mucosa, deferral of administration should be considered until resolution of the illness, or another appropriate vaccine should be administered instead.

Contraindications and precautions for the use of LAIV4: Per the package insert, LAIV4 is contraindicated for persons with a history of severe allergic reaction to any component of the vaccine or to a previous dose of any influenza vaccine, and in children and adolescents receiving concomitant aspirin or salicylate-containing medications (Table 2). While LAIV is an egg-based vaccine, ACIP makes specific recommendations for the use of influenza vaccine for persons with egg allergy (see Persons with a History of Egg Allergy). In addition to the labeled contraindications (other than allergy to egg), ACIP also recommends that LAIV should not be administered to the following groups:

- Children aged 2 through 4 years who have received a diagnosis of asthma or whose parents or caregivers report that a health care provider has told them during the preceding 12 months that their child had wheezing or asthma or whose medical record indicates a wheezing episode has occurred during the preceding 12 months;

- Persons who are immunocompromised due to any cause (including immunosuppression caused by medications and HIV infection);

- Close contacts and caregivers of severely immunosuppressed persons who require a protected environment;

- Pregnant women; and

- Persons who have received influenza antiviral medications within the previous 48 hours.

Moderate or severe acute illness with or without fever is a general precaution for vaccination (72). GBS within 6 weeks following a previous dose of influenza vaccine is considered a precaution for use of influenza vaccines. Additional precautions specific to LAIV4 
include asthma in persons aged $\geq 5$ years and presence of an underlying medical condition (other than the instances listed in which LAIV4 should not be used) that might predispose to complications after wild-type influenza infection (see Populations at Higher Risk for Medical Complications Attributable to Severe Influenza; Table 2).

\section{Recent Influenza Vaccine Product Approvals}

Since the publication of the previous season's guidance, there have been two labeling changes for previously licensed influenza vaccines. These include expansions in the age indications for Afluria Quadrivalent and Fluarix Quadrivalent.

\section{Afluria Quadrivalent (IIV4)}

In August 2017, FDA approved expansion of the licensed age indication for Afluria Quadrivalent. Previously licensed for persons aged $\geq 18$ years, Afluria Quadrivalent is now licensed for persons aged $\geq 5$ years. In a multicenter observer-blind trial in which 2,278 children aged 5 through 17 years were randomized 3:1 to receive Afluria Quadrivalent or a licensed comparator IIV4, Afluria Quadrivalent met criteria for noninferior immunogenicity for all four vaccine virus strains (97). The overall safety profiles were comparable. Fever occurred more frequently among Afluria Quadrivalent recipients, but the difference was not statistically significant. Myalgia was more frequent among Afluria Quadrivalent recipients aged 9 through 17 years, (relative risk: 1.50 ; $95 \% \mathrm{CI}=1.03-2.19$ ) but in most instances was mild to moderate in severity.

\section{Fluarix Quadrivalent (IIV4)}

In January 2018, FDA approved expansion of the licensed age indication for Fluarix Quadrivalent (IIV4). Previously licensed for persons aged $\geq 3$ years, Fluarix Quadrivalent is now licensed for persons aged $\geq 6$ months. The approved dose volume is $0.5 \mathrm{~mL}$ for all ages $(52,98)$.

In a multicenter randomized observer-blind controlled trial conducted among 12,018 children aged 6-35-months in 13 countries that compared the efficacy, immunogenicity, and safety of $0.5 \mathrm{~mL}$ Fluarix Quadrivalent with noninfluenza control vaccines (pneumococcal conjugate vaccine, hepatitis A vaccine, or varicella vaccine, depending upon participant age and prior influenza receipt status), vaccine efficacy (VE) of Fluarix Quadrivalent for reverse transcriptase polymerase chain reaction (RT-PCR)-confirmed influenza infection of any severity due to any virus was $50 \%(97.5 \% \mathrm{CI}=42-57)$. VE against moderate-to-severe RT-PCR-confirmed influenza was 63\% $(97.5 \% \mathrm{CI}=52-72)$. Moderate to severe influenza was defined as RT-PCR-confirmed influenza with any of the following: fever $>39.0^{\circ} \mathrm{C}$; physician-diagnosed acute otitis media, lower respiratory infection, or serious extrapulmonary complication of influenza; intensive care unit hospitalization; or requirement for supplemental oxygen for $>8$ hours. Considering culture-confirmed influenza due to viruses matching those in the vaccine, VE against influenza of any severity was $60 \%(95 \% \mathrm{CI}=49-69)$ and against moderate to severe influenza was $78 \%(95 \% \mathrm{CI}=64-87)$. Prevalence of injection site and systemic solicited reactions, unsolicited adverse events, and medically attended adverse events were generally similar between the treatment arms $(98,99)$.

\section{Storage and Handling of Influenza Vaccines}

In all instances, approved manufacturer packaging information should be consulted for authoritative guidance concerning storage and handling of all influenza vaccines. Vaccines should be protected from light and stored at recommended temperatures. In general, influenza vaccines are recommended to be stored refrigerated between $2^{\circ}$ to $8^{\circ} \mathrm{C}\left(36^{\circ}\right.$ to $\left.46^{\circ} \mathrm{F}\right)$ and should not be frozen. Vaccine that has frozen should be discarded. Singledose vials should not be accessed for more than one dose. Multiple-dose vials should be returned to recommended storage conditions between uses, and once first accessed should not be kept beyond the recommended period of time. For information on permissible temperature excursions and other departures from recommended storage conditions that are not discussed in the package labeling, contact the manufacturer. Vaccines should not be used after the expiration date on the label.

\section{Additional Sources for Information Regarding Influenza and Influenza Vaccines}

\section{Influenza Surveillance, Prevention, and Control}

Updated information regarding influenza surveillance, detection, prevention, and control is available at https://www. cdc.gov/flu. U.S surveillance data are updated weekly during October-May on FluView (https://www.cdc.gov/flu/weekly). In addition, periodic updates regarding influenza are published in MMWR (https://www.cdc.gov/mmwr). Additional information regarding influenza vaccine can be obtained from CDC-INFO by calling 1-800-232-4636. State and local health departments should be consulted about availability of influenza vaccine, access to vaccination programs, information related to state or local influenza activity, reporting of influenza outbreaks and influenzarelated pediatric deaths, and advice concerning outbreak control.

\section{Vaccine Adverse Event Reporting System}

The National Childhood Vaccine Injury Act of 1986 requires health care providers to report any adverse event listed by the vaccine 
manufacturer as a contraindication to further doses of the vaccine, or any adverse event listed in the VAERS Table of Reportable Events Following Vaccination (https://vaers.hhs.gov/docs/VAERS_Table_ of_Reportable_Events_Following_Vaccination.pdf) that occurs within the specified time period after vaccination. In addition to mandated reporting, health care providers are encouraged to report any clinically significant adverse event following vaccination to VAERS. Information on how to report a vaccine adverse event is available at https://vaers.hhs.gov/index.html. Additional information on VAERS and vaccine safety is available by emailing info@vaers.org or by calling 1-800-822-7967.

\section{National Vaccine Injury Compensation Program}

The National Vaccine Injury Compensation Program (VICP), established by the National Childhood Vaccine Injury Act of 1986, as amended, provides a mechanism through which compensation can be paid on behalf of a person determined to have been injured or to have died as a result of receiving a vaccine covered by VICP. The Vaccine Injury Table (https://www.hrsa.gov/ vaccinecompensation/vaccineinjurytable.pdf) lists the vaccines covered by VICP and the associated injuries and conditions (including death) that might receive a legal presumption of causation. If the injury or condition is not on the Table, or does not occur within the specified time period on the Table, persons must prove that the vaccine caused the injury or condition. Eligibility for compensation is not affected by whether a covered vaccine is used off-label or inconsistently with recommendations.

To be eligible for compensation under VICP, a claim must be filed within 3 years after the first symptom of the vaccine injury. Death claims must be filed within 2 years of the vaccinerelated death and not more than 4 years after the start of the first symptom of the vaccine-related injury from which the death occurred. When a new vaccine is covered by VICP or when a new injury/condition is added to the Table, claims that do not meet the general filing guidelines must be filed within 2 years from the date the vaccine or injury/condition is added to the Table for injuries or deaths that occurred up to 8 years before the Table change (100). Persons of all ages who receive a VICP-covered vaccine might be eligible to file a claim. Additional information is available at https://www. hrsa.gov/vaccinecompensation or by calling 1-800-338-2382.

\section{Additional Resources}

\section{ACIP Statements}

- General Best Practice Guidelines for Immunization: Best Practices Guidance of the Advisory Committee on
Immunization Practices (ACIP). https://www.cdc.gov/ vaccines/hcp/acip-recs/general-recs/index.html

- Immunization of Healthcare Personnel: Recommendations of the Advisory Committee on Immunization Practices (ACIP), 2011. MMWR Recomm Rep 2011;60(No. RR-7). https:// www.cdc.gov/mmwr/preview/mmwrhtml/rr6007a1.htm

- Recommended Immunization Schedules for Adults Aged 19 Years or Older, United States, 2018. https://www.cdc. gov/vaccines/schedules/hcp/adult.html

- Recommended Immunization Schedule for Children and Adolescents Aged 18 years or Younger, United States, 2018. https://www.cdc.gov/vaccines/schedules/hcp/childadolescent.html

\section{Vaccine Information Sheets (VISs)}

- VIS for IIV and RIV: https://www.cdc.gov/vaccines/hcp/ vis/vis-statements/flu.pdf

- VIS for LAIV: https://www.cdc.gov/vaccines/hcp/vis/visstatements/flulive.pdf

\section{Influenza Vaccine Package Inserts}

- Trivalent Vaccines: https://www.fda.gov/BiologicsBloodVaccines/ Vaccines/ApprovedProducts/ucm094045.htm

- Quadrivalent Vaccines: https://www.fda.gov/ BiologicsBloodVaccines/Vaccines/ApprovedProducts/ ucm295057.htm

\section{CDC Influenza Antiviral Guidance}

- Antiviral Drugs: Information for Healthcare Professionals: https://www.cdc.gov/flu/professionals/antivirals/index.htm

\section{American Academy of Pediatrics (AAP) Guidance}

- AAP Recommendations for Prevention and Control of Influenza in Children (Red Book Online): https://redbook. solutions.aap.org/ss/influenza-resources.aspx

\section{Infectious Diseases Society of America (IDSA) Guidance}

- 2013 IDSA Clinical Practice Guideline for Vaccination of the Immunocompromised Host: https://academic.oup. com/cid/article/58/3/e44/336537

\section{American College of Obstetricians and Gynecologists (ACOG)}

- Influenza Vaccination During Pregnancy, ACOG Committee Opinion No. 732: https://www.acog.org/ Clinical-Guidance-and-Publications/CommitteeOpinions/Committee-on-Obstetric-Practice/ Influenza-Vaccination-During-Pregnancy 


\section{References}

1. Barker WH. Excess pneumonia and influenza associated hospitalization during influenza epidemics in the United States, 1970-78. Am J Public Health 1986;76:761-5. https://doi.org/10.2105/AJPH.76.7.761

2. Barker WH, Mullooly JP. Impact of epidemic type A influenza in a defined adult population. Am J Epidemiol 1980;112:798-813. https:// doi.org/10.1093/oxfordjournals.aje.a113052

3. Poehling KA, Edwards KM, Griffin MR, et al. The burden of influenza in young children, 2004-2009. Pediatrics 2013;131:207-16. https:// doi.org/10.1542/peds.2012-1255

4. Poehling KA, Edwards KM, Weinberg GA, et al.; New Vaccine Surveillance Network. The underrecognized burden of influenza in young children. N Engl J Med 2006;355:31-40. https://doi. org/10.1056/NEJMoa054869

5. Siston AM, Rasmussen SA, Honein MA, et al.; Pandemic H1N1 Influenza in Pregnancy Working Group. Pandemic 2009 influenza $\mathrm{A}(\mathrm{H} 1 \mathrm{~N} 1)$ virus illness among pregnant women in the United States. JAMA 2010;303:1517-25. https://doi.org/10.1001/jama.2010.479

6. Mullooly JP, Bridges CB, Thompson WW, et al.; Vaccine Safety Datalink Adult Working Group. Influenza- and RSV-associated hospitalizations among adults. Vaccine 2007;25:846-55. https://doi.org/10.1016/j. vaccine.2006.09.041

7. Fiore AE, Uyeki TM, Broder K, et al.; CDC. Prevention and control of influenza with vaccines: recommendations of the Advisory Committee on Immunization Practices (ACIP), 2010. MMWR Recomm Rep 2010;59(No. RR-8):1-62.

8. Grohskopf LA, Sokolow LZ, Broder KR, et al. Prevention and control of seasonal influenza with vaccines: recommendations of the Advisory Committee on Immunization Practices-United States, 2017-18 influenza season. MMWR Recomm Rep 2017;66:(No. RR-2)1-20. https://doi.org/10.15585/mmwr.rr6602a1

9. Advisory Committee on Immunization Practices. Summary report: February 24, 2016 (Meeting minutes). Atlanta, GA: US Department of Health and Human Services, CDC; 2016.

10. Des Roches A, Samaan K, Graham F, et al. Safe vaccination of patients with egg allergy by using live attenuated influenza vaccine. J Allergy Clin Immunol Pract 2015;3:138-9. https://doi.org/10.1016/j.jaip.2014.08.008

11. Turner PJ, Southern J, Andrews NJ, Miller E, Erlewyn-Lajeunesse M; SNIFFLE-2 Study Investigators. Safety of live attenuated influenza vaccine in young people with egg allergy: multicentre prospective cohort study. BMJ 2015;351:h6291. https://doi.org/10.1136/bmj.h6291

12. Turner PJ, Southern J, Andrews NJ, et al.; SNIFFLE Study Investigators. Safety of live attenuated influenza vaccine in atopic children with egg allergy. J Allergy Clin Immunol 2015;136:376-81. https://doi. org/10.1016/j.jaci.2014.12.1925

13. CDC. The flu season. Atlanta, GA: US Department of Health and Human Services, CDC; 2015. https://www.cdc.gov/flu/about/season/ flu-season.htm

14. Castilla J, Martínez-Baz I, Martínez-Artola V, et al.; Primary Health Care Sentinel Network; Network for Influenza Surveillance in Hospitals of Navarre. Decline in influenza vaccine effectiveness with time after vaccination, Navarre, Spain, season 2011/12. Euro Surveill 2013;18:20388. https://doi.org/10.2807/ese.18.05.20388-en

15. Belongia EA, Sundaram ME, McClure DL, Meece JK, Ferdinands J, VanWormer JJ. Waning vaccine protection against influenza A (H3N2) illness in children and older adults during a single season. Vaccine 2015;33:246-51. https://doi.org/10.1016/j.vaccine.2014.06.052

16. Ferdinands JM, Fry AM, Reynolds S, et al. Intraseason waning of influenza vaccine protection: Evidence from the US Influenza Vaccine Effectiveness Network, 2011-12 through 2014-15. Clin Infect Dis 2017;64:544-50.
17. Kissling E, Valenciano M, Larrauri A, et al. Low and decreasing vaccine effectiveness against influenza $\mathrm{A}(\mathrm{H} 3)$ in 2011/12 among vaccination target groups in Europe: results from the I-MOVE multicentre casecontrol study. Euro Surveill 2013;18:20390. https://doi.org/10.2807/ ese.18.05.20390-en

18. Pebody R, Andrews N, McMenamin J, et al. Vaccine effectiveness of 2011/12 trivalent seasonal influenza vaccine in preventing laboratoryconfirmed influenza in primary care in the United Kingdom: evidence of waning intra-seasonal protection. Euro Surveill 2013;18:20389. https://doi.org/10.2807/ese.18.05.20389-en

19. Puig-Barberà J, Mira-Iglesias A, Tortajada-Girbés M, et al.; Valencia Hospital Network for the Study of Influenza and other Respiratory Viruses (VAHNSI, Spain). Waning protection of influenza vaccination during four influenza seasons, 2011/2012 to 2014/2015. Vaccine 2017;35:5799-807. https://doi.org/10.1016/j.vaccine.2017.09.035

20. Radin JM, Hawksworth AW, Myers CA, Ricketts MN, Hansen EA, Brice GT. Influenza vaccine effectiveness: maintained protection throughout the duration of influenza seasons 2010-2011 through 2013-2014. Vaccine 2016;34:3907-12. https://doi.org/10.1016/j. vaccine.2016.05.034

21. Kissling E, Nunes B, Robertson C, et al.; I-MOVE case-control study team. I-MOVE multicentre case-control study 2010/11 to 2014/15: is there within-season waning of influenza type/subtype vaccine effectiveness with increasing time since vaccination? Euro Surveill 2016;21.

22. Petrie JG, Ohmit SE, Truscon R, et al. Modest waning of influenza vaccine efficacy and antibody titers during the 2007-2008 influenza season. J Infect Dis 2016;214:1142-9. https://doi.org/10.1093/infdis/ jiw105

23. CDC. Immunization of health-care personnel: recommendations of the Advisory Committee on Immunization Practices (ACIP). MMWR Recomm Rep 2011;60(No. RR-7):1-45.

24. Pearson ML, Bridges CB, Harper SA; Healthcare Infection Control Practices Advisory Committee (HICPAC); Advisory Committee on Immunization Practices (ACIP). Influenza vaccination of health-care personnel: recommendations of the Healthcare Infection Control Practices Advisory Committee (HICPAC) and the Advisory Committee on Immunization Practices (ACIP). MMWR Recomm Rep 2006;55(No. RR-2):1-16.

25. Wright PF, Thompson J, Vaughn WK, Folland DS, Sell SH, Karzon DT. Trials of influenza A/New Jersey/76 virus vaccine in normal children: an overview of age-related antigenicity and reactogenicity. J Infect Dis 1977;136(Suppl 3):S731-41. https://doi.org/10.1093/infdis/136. Supplement_3.S731

26. Wright PF, Dolin R, La Montagne JR. Summary of clinical trials of influenza vaccines-II. J Infect Dis 1976;134:633-8. https://doi. org/10.1093/infdis/134.6.633

27. Wright PF, Sell SH, Thompson J, Karzon DT. Clinical reactions and serologic response following inactivated monovalent influenza type B vaccine in young children and infants. J Pediatr 1976;88:31-5. https:// doi.org/10.1016/S0022-3476(76)80722-6

28. Gross PA. Reactogenicity and immunogenicity of bivalent influenza vaccine in one- and two-dose trials in children: a summary. J Infect Dis 1977;136(Suppl 3):S616-25. https://doi.org/10.1093/infdis/136. Supplement_3.S616

29. Bernstein DI, Zahradnik JM, DeAngelis CJ, Cherry JD. Clinical reactions and serologic responses after vaccination with whole-virus or split-virus influenza vaccines in children aged 6 to 36 months. Pediatrics 1982;69:404-8.

30. Jain VK, Domachowske JB, Wang L, et al. Time to change dosing of inactivated quadrivalent influenza vaccine in young children: evidence from a Phase III, randomized, controlled trial. J Pediatric Infect Dis Soc 2017;6:9-19. 
31. Neuzil KM, Jackson LA, Nelson J, et al. Immunogenicity and reactogenicity of 1 versus 2 doses of trivalent inactivated influenza vaccine in vaccine-naive 5-8-year-old children. J Infect Dis 2006;194:1032-9. https://doi.org/10.1086/507309

32. Allison MA, Daley MF, Crane LA, et al. Influenza vaccine effectiveness in healthy 6- to 21-month-old children during the 2003-2004 season. J Pediatr 2006;149:755-62. https://doi.org/10.1016/j.jpeds.2006.06.036

33. Ritzwoller DP, Bridges CB, Shetterly S, Yamasaki K, Kolczak M, France EK. Effectiveness of the 2003-2004 influenza vaccine among children 6 months to 8 years of age, with 1 vs 2 doses. Pediatrics 2005;116:153-9. https://doi.org/10.1542/peds.2005-0049

34. Eisenberg KW, Szilagyi PG, Fairbrother G, et al.; New Vaccine Surveillance Network. Vaccine effectiveness against laboratory-confirmed influenza in children 6 to 59 months of age during the 2003-2004 and 2004-2005 influenza seasons. Pediatrics 2008;122:911-9. https://doi. org/10.1542/peds.2007-3304

35. ACOG Committee on Obstetric Practice. ACOG Committee Opinion No. 732. Influenza vaccination during pregnancy. Obstet Gynecol 2018;131:e109-14. https://doi.org/10.1097/AOG.0000000000002588

36. ACOG Committee on Obstetric Practice. ACOG Committee Opinion No. 732. Mummary: influenza vaccination during pregnancy. Obstet Gynecol 2018;131:752-3. https://doi.org/10.1097/AOG.0000000000002586

37. ACOG Immunization, Infectious Disease, and Public Health Preparedness Expert Work Group. ACOG Committee Opinion No. 741. Maternal immunization. Obstet Gynecol 2018;131:e214-7. https://doi.org/10.1097/AOG.0000000000002665

38. Donahue JG, Kieke BA, King JP, et al. Association of spontaneous abortion with receipt of inactivated influenza vaccine containing H1N1pdm09 in 2010-11 and 2011-12. Vaccine 2017;35:5314-22. https://doi.org/10.1016/j.vaccine.2017.06.069

39. Chambers CD, Johnson DL, Xu R, et al.; OTIS Collaborative Research Group. Safety of the 2010-11, 2011-12, 2012-13, and 2013-14 seasonal influenza vaccines in pregnancy: birth defects, spontaneous abortion, preterm delivery, and small for gestational age infants, a study from the cohort arm of VAMPSS. Vaccine 2016;34:4443-9. https:// doi.org/10.1016/j.vaccine.2016.06.054

40. Huang WT, Tang FW, Yang SE, Chih YC, Chuang JH. Safety of inactivated monovalent pandemic (H1N1) 2009 vaccination during pregnancy: a population-based study in Taiwan. Vaccine 2014;32:6463-8. https://doi.org/10.1016/j.vaccine.2014.09.054

41. Ma F, Zhang L, Jiang R, et al. Prospective cohort study of the safety of an influenza $\mathrm{A}(\mathrm{H} 1 \mathrm{~N} 1)$ vaccine in pregnant Chinese women. Clin Vaccine Immunol 2014;21:1282-7. https://doi.org/10.1128/CVI.00375-14

42. Irving SA, Kieke BA, Donahue JG, et al.; Vaccine Safety Datalink. Trivalent inactivated influenza vaccine and spontaneous abortion. Obstet Gynecol 2013;121:159-65. https://doi.org/10.1097/AOG.0b013e318279f56f

43. Chambers CD, Johnson D, Xu R, et al. Risks and safety of pandemic H1N1 influenza vaccine in pregnancy: birth defects, spontaneous abortion, preterm delivery, and small for gestational age infants. Vaccine 2013;31:5026-32.

44. Oppermann M, Fritzsche J, Weber-Schoendorfer C, et al. A(H1N1) v2009: a controlled observational prospective cohort study on vaccine safety in pregnancy. Vaccine 2012;30:4445-52. https://doi.org/10.1016/j. vaccine.2012.04.081

45. Pasternak B, Svanström H, Mølgaard-Nielsen D, et al. Vaccination against pandemic $\mathrm{A} / \mathrm{H} 1 \mathrm{~N} 12009$ influenza in pregnancy and risk of fetal death: cohort study in Denmark. BMJ 2012;344:e2794. https://doi. org/10.1136/bmj.e2794

46. Sammon CJ, Snowball J, McGrogan A, de Vries CS. Evaluating the hazard of foetal death following $\mathrm{H} 1 \mathrm{~N} 1$ influenza vaccination; a population based cohort study in the UK GPRD. PLoS One 2012;7:e51734. https://doi.org/10.1371/journal.pone.0051734

47. Heikkinen T, Young J, van Beek E, et al. Safety of MF59-adjuvanted A/ H1N1 influenza vaccine in pregnancy: a comparative cohort study. Am J Obstet Gynecol 2012;207:177 e1-8.
48. McMillan M, Porritt K, Kralik D, Costi L, Marshall H. Influenza vaccination during pregnancy: a systematic review of fetal death, spontaneous abortion, and congenital malformation safety outcomes. Vaccine 2015;33:2108-17. https://doi.org/10.1016/j.vaccine.2015.02.068

49. Bratton KN, Wardle MT, Orenstein WA, Omer SB. Maternal influenza immunization and birth outcomes of stillbirth and spontaneous abortion: a systematic review and meta-analysis. Clin Infect Dis 2015;60:e11-9. https://doi.org/10.1093/cid/ciu915

50. Advisory Committee on Immunization Practices. Summary report: October 25-26, 2017 (Meeting minutes). Atlanta, GA: US Department of Health and Human Services, CDC; 2017.

51. FluLaval Quadrivalent [Package Insert]. Quebec City, Quebec, Canada: ID Biomedical Corporation of Quebec; 2018.

52. Fluarix Quadrivalent [Package Insert]. Research Triangle Park, North Carolina: GlaxoSmithKline; 2018.

53. Afluria Quadrivalent [Package Insert]. Parkville, Victoria, Australia: Seqirus; 2018.

54. Flucelvax Quadrivalent [Package Insert]. Holly Springs, NC: Seqirus; 2018.

55. Flublok Quadrivalent [Package Insert]. Swiftwater, PA: Sanofi Pasteur; 2018.

56. Fluzone Quadrivalent. Swiftwater, PA: Sanofi Pasteur; 2018.

57. DiazGranados CA, Dunning AJ, Kimmel M, et al. Efficacy of high-dose versus standard-dose influenza vaccine in older adults. N Engl J Med 2014;371:635-45. https://doi.org/10.1056/NEJMoa1315727

58. DiazGranados CA, Robertson CA, Talbot HK, Landolfi V, Dunning AJ, Greenberg DP. Prevention of serious events in adults 65 years of age or older: a comparison between high-dose and standard-dose inactivated influenza vaccines. Vaccine 2015;33:4988-93. https://doi.org/10.1016/j. vaccine.2015.07.006

59. Dunkle LM, Izikson R, Patriarca P, et al.; PSC12 Study Team. Efficacy of recombinant influenza vaccine in adults 50 years of age or older. N Engl J Med 2017;376:2427-36. https://doi.org/10.1056/ NEJMoa1608862

60. Van Buynder PG, Konrad S, Van Buynder JL, et al. The comparative effectiveness of adjuvanted and unadjuvanted trivalent inactivated influenza vaccine (TIV) in the elderly. Vaccine 2013;31:6122-8. https:// doi.org/10.1016/j.vaccine.2013.07.059

61. Clinical Review: Fluad. Silver Spring, MD: US Department of Health and Human Services, Food and Drug Administration; 2014.

62. Falsey AR, Treanor JJ, Tornieporth N, Capellan J, Gorse GJ. Randomized, double-blind controlled phase 3 trial comparing the immunogenicity of high-dose and standard-dose influenza vaccine in adults 65 years of age and older. J Infect Dis 2009;200:172-80. https://doi. org/10.1086/599790

63. Fluzone High-Dose [Package Insert]. Swiftwater, PA: Sanofi Pasetur; 2018.

64. Food and Drug Administration. October 29, 2014 clinical reviewFluzone High-Dose. Silver Spring, MD: US Department of Health and Human Services, Food and Drug Administration; 2014.

65. Gravenstein S, Davidson HE, Taljaard M, et al. Comparative effectiveness of high-dose versus standard-dose influenza vaccination on numbers of US nursing home residents admitted to hospital: a cluster-randomised trial. Lancet Respir Med 2017;5:738-46. https://doi.org/10.1016/ S2213-2600(17)30235-7

66. Young-Xu Y, Van Aalst R, Mahmud SM, et al. Relative vaccine effectiveness of high-dose versus standard-dose influenza vaccines among Veterans Health Administration patients. J Infect Dis 2018;217:171827. https://doi.org/10.1093/infdis/jiy088

67. Richardson DM, Medvedeva EL, Roberts CB, Linkin DR; CDC Epicenter Program. Comparative effectiveness of high-dose versus standard-dose influenza vaccination in community-dwelling veterans. Clin Infect Dis 2015;61:171-6. https://doi.org/10.1093/cid/civ261 
68. Shay DK, Chillarige Y, Kelman J, et al. Comparative effectiveness of high-dose versus standard-dose influenza vaccines among US Medicare beneficiaries in preventing postinfluenza deaths during 2012-2013 and 2013-2014. J Infect Dis 2017;215:510-7. https://doi.org/10.1093/ infdis/jiw641

69. Izurieta HS, Thadani N, Shay DK, et al. Comparative effectiveness of high-dose versus standard-dose influenza vaccines in US residents aged 65 years and older from 2012 to 2013 using Medicare data: a retrospective cohort analysis. Lancet Infect Dis 2015;15:293-300. https://doi.org/10.1016/S1473-3099(14)71087-4

70. Lee JKH, Lam GKL, Shin T, et al. Efficacy and effectiveness of high-dose versus standard-dose influenza vaccination for older adults: a systematic review and meta-analysis. Expert Rev Vaccines 2018;17:435-43.

71. Food and Drug Administration. Summary basis for regulatory actionFlublok Quadrivalent. Silver Spring, MD: US Department of Health and Human Services, Food and Drug Administration; 2016.

72. Kroger AT, Duchin J, Vázquez M. Best practices guidance of the Advisory Committee on Immunization Practices (ACIP). Atlanta, GA: US Department of Health and Human Services, CDC; 2017. https://www. cdc.gov/vaccines/hcp/acip-recs/general-recs/downloads/general-recs.pdf

73. Rubin LG, Levin MJ, Ljungman P, et al.; Infectious Diseases Society of America. 2013 IDSA clinical practice guideline for vaccination of the immunocompromised host. Clin Infect Dis 2014;58:e44-100. https:// doi.org/10.1093/cid/cit684

74. CDC. Antiviral drugs: information for healthcare professionals. Atlanta, GA: US Department of Health and Human Services, CDC. https:// www.cdc.gov/flu/professionals/antivirals/index.htm

75. Erlewyn-Lajeunesse M, Brathwaite N, Lucas JS, Warner JO. Recommendations for the administration of influenza vaccine in children allergic to egg. BMJ 2009;339(sep153):b3680. https://doi.org/10.1136/ bmj.b3680

76. CDC. Advisory Committee on Immunization Practices summary report: June 20-21, 2012 (meeting minutes). Atlanta, GA: US Department of Health and Human Services, CDC; 2012.

77. CDC. Advisory Committee on Immunization Practices summary report: June 19-20, 2013 (meeting minutes). Atlanta, GA: US Department of Health and Human Services, CDC; 2013.

78. Miller JM, Tam TW, Maloney S, et al. Cruise ships: high-risk passengers and the global spread of new influenza viruses. Clin Infect Dis 2000;31:433-8. https://doi.org/10.1086/313974

79. Uyeki TM, Zane SB, Bodnar UR, et al.; Alaska/Yukon Territory Respiratory Outbreak Investigation Team. Large summertime influenza A outbreak among tourists in Alaska and the Yukon Territory. Clin Infect Dis 2003;36:1095-102. https://doi.org/10.1086/374053

80. Mutsch M, Tavernini M, Marx A, et al. Influenza virus infection in travelers to tropical and subtropical countries. Clin Infect Dis 2005;40:1282-7. https://doi.org/10.1086/429243

81. Ratnam I, Black J, Leder K, et al. Incidence and risk factors for acute respiratory illnesses and influenza virus infections in Australian travellers to Asia. J Clin Virol 2013;57:54-8. https://doi.org/10.1016/j.jcv.2013.01.008

82. Flumist Quadrivalent [Package Insert]. Gaithersburg, Maryland: MedImmune; 2018.

83. Kerzner B, Murray AV, Cheng E, et al. Safety and immunogenicity profile of the concomitant administration of ZOSTAVAX and inactivated influenza vaccine in adults aged 50 and older. J Am Geriatr Soc 2007;55:1499-507. https://doi.org/10.1111/j.1532-5415.2007.01397.x

84. Frenck RW Jr, Gurtman A, Rubino J, et al. Randomized, controlled trial of a 13-valent pneumococcal conjugate vaccine administered concomitantly with an influenza vaccine in healthy adults. Clin Vaccine Immunol 2012;19:1296-303. https://doi.org/10.1128/CVI.00176-12

85. Schwarz TF, Flamaing J, Rümke HC, et al. A randomized, double-blind trial to evaluate immunogenicity and safety of 13 -valent pneumococcal conjugate vaccine given concomitantly with trivalent influenza vaccine in adults aged $\geq 65$ years. Vaccine 2011;29:5195-202. https://doi. org/10.1016/j.vaccine.2011.05.031
86. McNeil SA, Noya F, Dionne M, et al. Comparison of the safety and immunogenicity of concomitant and sequential administration of an adult formulation tetanus and diphtheria toxoids adsorbed combined with acellular pertussis (Tdap) vaccine and trivalent inactivated influenza vaccine in adults. Vaccine 2007;25:3464-74. https://doi. org/10.1016/j.vaccine.2006.12.047

87. Song JY, Cheong HJ, Tsai TF, et al. Immunogenicity and safety of concomitant MF59-adjuvanted influenza vaccine and 23-valent pneumococcal polysaccharide vaccine administration in older adults. Vaccine 2015;33:4647-52. https://doi.org/10.1016/j.vaccine.2015.05.003

88. Sukumaran L, McCarthy NL, Kharbanda EO, et al. Safety of tetanus toxoid, reduced diphtheria toxoid, and acellular pertussis and influenza vaccinations in pregnancy. Obstet Gynecol 2015;126:1069-74. https:// doi.org/10.1097/AOG.0000000000001066

89. Stockwell MS, Broder K, LaRussa P, et al. Risk of fever after pediatric trivalent inactivated influenza vaccine and 13-valent pneumococcal conjugate vaccine. JAMA Pediatr 2014;168:211-9. https://doi. org/10.1001/jamapediatrics.2013.4469

90. Duffy J, Weintraub E, Hambidge SJ, et al.; Vaccine Safety Datalink. Febrile seizure risk after vaccination in children 6 to 23 months. Pediatrics 2016;138:e20160320. https://doi.org/10.1542/peds.2016-0320

91. Li R, Stewart B, McNeil MM, et al. Post licensure surveillance of influenza vaccines in the Vaccine Safety Datalink in the 2013-2014 and 2014-2015 seasons. Pharmacoepidemiol Drug Saf 2016;25:92834. https://doi.org/10.1002/pds.3996

92. Patterson JL, Carapetian SA, Hageman JR, Kelley KR. Febrile seizures. Pediatr Ann 2013;42:e258-63. https://doi.org/10.3928/00904481-20131122-09

93. Nolan T, Bernstein DI, Block SL, et al.; LAIV Study Group. Safety and immunogenicity of concurrent administration of live attenuated influenza vaccine with measles-mumps-rubella and varicella vaccines to infants 12 to 15 months of age. Pediatrics 2008;121:508-16. https:// doi.org/10.1542/peds.2007-1064

94. Lum LC, Borja-Tabora CF, Breiman RF, et al. Influenza vaccine concurrently administered with a combination measles, mumps, and rubella vaccine to young children. Vaccine 2010;28:1566-74. https:// doi.org/10.1016/j.vaccine.2009.11.054

95. Schwarz TF, Aggarwal N, Moeckesch B, et al. Immunogenicity and safety of an adjuvanted herpes zoster subunit vaccine coadministered with aged seasonal influenza vaccine in adults 50 years or older. J Infect Dis 2017;216:1352-61. https://doi.org/10.1093/infdis/jix481

96. Afluria [Package Insert]. Parkville, Victoria, Australia: Seqirus; 2018.

97. Airey J, Albano FR, Sawlwin DC, et al. Immunogenicity and safety of a quadrivalent inactivated influenza virus vaccine compared with a comparator quadrivalent inactivated influenza vaccine in a pediatric population: A phase 3, randomized noninferiority study. Vaccine 2017;35:2745-52.

98. Clinical Review. (STN: 125127/834)_Fluarix Quadrivalent. Sliver Spring, MD: US Department of Health and Human Services, Food and Drug Administration; 2018. https://www.fda.gov/downloads/ BiologicsBloodVaccines/Vaccines/ApprovedProducts/UCM593001.pdf

99. Claeys C, Zaman K, Dbaibo G, et al. Prevention of vaccine-matched and mismatched influenza in children aged 6-35 months: a multinational randomized trial across five influenza seasons. Lancet Child Adolesc Health 2018;2:338-49.

100. Health Resources and Services Administration. What you need to know about the National Vaccine Injury Compensation Program (VICP). Washington, DC: US Department of Health and Human Services, Health Resources and Services Administration; 2016. 


\section{Disclosure of Relationship}

Emmanuel B. Walter reports grants from Novavax and Merck \& Co, outside the submitted work. Other content experts and CDC planners wish to disclose they have no financial interests or other relationships with the manufacturers of commercial products, suppliers of commercial services, or commercial supporters. This report includes discussion of the unlabeled use of influenza vaccines in the instance of vaccination of persons with a history of egg allergy. A history of severe allergic reaction to influenza vaccine or any of its components (including egg) is a labeled contraindication to receipt of most IIVs and LAIV. However, ACIP and CDC recommend that persons with egg allergy of any severity should receive any licensed, recommended, and ageappropriate influenza vaccine that is otherwise appropriate for their health status. Persons with a history of severe allergic reaction to egg should be vaccinated in an inpatient or outpatient medical setting (including, but not necessarily limited to, hospitals, clinics, health departments, and physician offices). Vaccine administration should be supervised by a health care provider who is able to recognize and manage severe allergic conditions. No postvaccination observation period is recommended specifically for egg-allergic persons. However, ACIP recommends that vaccine providers consider observing patients (seated or supine) for 15 minutes following administration of any vaccine to decrease the risk for injury should syncope occur. 


\section{Advisory Committee on Immunization Practices (ACIP), July 1, 2017-June 30, 2018}

Chair: Nancy Bennett, MD, University of Rochester School of Medicine and Dentistry, Rochester, New York.

Executive Secretary: Amanda Cohn, MD, National Center for Immunization and Respiratory Diseases, CDC, Atlanta, Georgia.

Members: Robert L. Atmar, MD, Baylor College of Medicine, Houston, Texas; Edward Belongia, MD, Marshfield Clinic Research Foundation, Marshfield, Wisconsin; Henry Bernstein, DO, Cohen Children's Medical Center, New Hyde Park, New York; Echezona Ezeanolue, MD, University of Nevada, Las Vegas, Nevada; Sharon E. Frey, MD, St. Louis University Medical School, St. Louis, Missouri; Paul Hunter, MD, University of Wisconsin School of Medicine and Public Health, Milwaukee, Wisconsin; Grace M. Lee, MD, Stanford University School of Medicine, Stanford, California; Kelly Moore, MD, Vanderbilt University School of Medicine, Nashville, Tennessee; Cynthia Pellegrini, March of Dimes, District of Columbia; Laura E. Riley, MD, Harvard Medical School, Boston, Massachusetts; José R. Romero, MD, University of Arkansas for Medical Sciences, Little Rock, Arkansas; David Stephens, MD, Emory University School of Medicine, Atlanta, Georgia; Peter Szilagyi, MD, University of California, Los Angeles, California; Emmanuel (Chip) Walter, MD, Duke University School of Medicine, Durham, North Carolina.

Ex Officio Members: Centers for Medicare and Medicaid Services (CMS), Mary Beth Hance, Baltimore, Maryland; Department of Defense (DOD), Eric Deussing, MD, Atlanta, Georgia; Department of Veterans Affairs (DVA), Jane A. Kim, MD, Durham, North Carolina; Food and Drug Administration (FDA), Wellington Sun, MD, Rockville, Maryland; Health Resources and Services Administration (HRSA), Narayan Nair, MD, Rockville, Maryland; Indian Health Service (IHS), Amy Groom, MPH, Albuquerque, New Mexico; National Vaccine Program Office (NVPO), Angela K. Shen, ScD, District of Columbia; National Institutes of Health (NIH), Linda C. Lambert, PhD, Bethesda, Maryland.

Liaison Representatives: American Academy of Family Physicians (AAFP), Pamela G. Rockwell, DO, Ann Arbor, Michigan; American Academy of Pediatrics (AAP), Committee on Infectious Diseases (COID), Carrie L. Byington, MD, Bryan, Texas; American Academy of Pediatrics (AAP), Red Book Editor, David Kimberlin, MD, Birmingham, Alabama; American Academy of Physician Assistants (AAPA), Marie-Michèle Léger, MPH, Alexandria, Virginia; American College Health Association (ACHA), Susan Even, MD, Columbia, Missouri; American College of Nurse Midwives (ACNM), Carol E. Hayes, MN, MPH, Atlanta, Georgia; American College of Nurse Midwives (ACNM), (alternate) Pamela M. Meharry, PhD, Chicago, Illinois; American College of Obstetricians and Gynecologists (ACOG), Kevin A. Ault, MD, Kansas City, Kansas; American College of Physicians (ACP), Sandra Adamson Fryhofer, MD, Atlanta, Georgia; American College of Physicians (ACP) (alternate), Gregory A. Poland, MD, Rochester, Minnesota; American Geriatrics Society (AGS), Kenneth Schmader, MD, Durham, North Carolina; America's Health Insurance Plans (AHIP), Mark J. Netoskie, MD, Houston, Texas; American Medical Association (AMA), Sandra Adamson Fryhofer, MD, Atlanta, Georgia; American Nurses Association (ANA), Charles (Chad) Rittle, DNP, Pittsburgh, Pennsylvania; American Osteopathic Association (AOA), Stanley E. Grogg, DO, Tulsa, Oklahoma; American Pharmacists Association (APhA), Stephan L. Foster, PharmD, Memphis, Tennessee; Association of Immunization Managers (AIM), Christine Finley, MPH, Burlington, Vermont; Association for Prevention Teaching and Research (APTR), W. Paul McKinney, MD, Louisville, Kentucky; Association of State and Territorial Health Officials (ASTHO), Nathaniel Smith, MD, Little Rock, Arkansas; Biotechnology Industry Organization (BIO) Phyllis A. Arthur, MBA, Washington, District of Columbia; Council of State and Territorial Epidemiologists (CSTE), Christine Hahn, MD, Boise, Idaho; Canadian National Advisory Committee on Immunization (NACI), Caroline Quach, MD, Montreal, Québec, Canada; Infectious Diseases Society of America (IDSA), Kathleen M. Neuzil, MD, Baltimore, Maryland; Infectious Diseases Society of America (IDSA) (alternate), Carol J. Baker, MD, Houston, Texas; National Association of County and City Health Officials (NACCHO), Matthew Zahn, MD, Santa Ana, California; National Association of County and City Health Officials (NACCHO), (alternate) Jeffrey Duchin, MD, Seattle, Washington; National Association of Pediatric Nurse Practitioners (NAPNAP), Patricia A. Stinchfield, MS, St. Paul, Minnesota; National Foundation for Infectious Diseases (NFID), William Schaffner, MD, Nashville, Tennessee; National Immunization Council and Child Health Program, Mexico, Luis Durán, MD, Mexico City, Mexico; National Medical Association (NMA), Patricia Whitley-Williams, MD, New Brunswick, New Jersey; National Vaccine Advisory Committee (NVAC), Kimberly Thompson, ScD, Orlando, Florida; Pediatric Infectious Diseases Society (PIDS), Sean O'Leary, MD, Aurora, Colorado; Pediatric Infectious Diseases Society (PIDS) (alternate), Mark H. Sawyer, MD, San Diego, California; Pharmaceutical Research and Manufacturers of America (PhRMA), David R. Johnson, MD, Swiftwater, Pennsylvania; Society for Adolescent Health and Medicine (SAHM), Amy B. Middleman, MD, Oklahoma City, Oklahoma; Society for Healthcare Epidemiology of America (SHEA), David Weber, MD, Chapel Hill, North Carolina.

\section{ACIP Influenza Vaccine Work Group}

Chair: Emmanuel (Chip) Walter, MD, Durham, North Carolina.

Members: Robert Atmar, MD, Houston, Texas; Kevin Ault, MD, Kansas, City, Kansas; Edward Belongia, MD, Marshfield, Wisconsin; Henry Bernstein, DO, Hempstead, New York; Karin Bok, PhD, Bethesda, Maryland; Sarah Coles, MD, Phoenix, Arizona; Clarence B. Creech, MD, Nashville, Tennessee; Sarah Despres, JD, District of Columbia; Jeff Duchin, MD, Seattle, Washington; David Cho, PhD, Silver Spring, Maryland; Janet Englund, MD, Seattle, Washington; Sandra Fryhofer, MD, Atlanta, Georgia; Ian Gemmill, MD, Kingston, Ontario, Canada; Ruth Karron, MD, Baltimore, Maryland; Wendy Keitel, MD, Houston, Texas; Lucia Lee, MD, Silver Spring, Maryland; Marie-Michèle Léger, MPH, Alexandria, Virginia; Susan Lett, MD, Jamaica Plain, Massachusetts; Jamie Loehr, MD, Ithaca, New York; Flor M. Munoz, MD, Houston, Texas; Kathleen M. Neuzil, MD, Baltimore, Maryland; Cynthia Nolletti, MD, Silver Spring, Maryland; Roshan Ramanathan, MD, Silver Spring, Maryland; Chris Roberts, PhD, Rockville, Maryland; William Schaffner, MD, Nashville, Tennessee; Robert Schechter, MD, Richmond, California; Kenneth Schmader, MD, Durham, North Carolina; Tamara Sheffield, MD, Salt Lake City, Utah; Patricia Stinchfield, MS, St. Paul, Minnesota; Rob Stirling, MD, Toronto, Ontario, Canada; Peter Szilagyi, MD, Los Angeles, California; Wendy Vaudry, MD, Edmonton, Alberta, Canada; Matthew Zahn, MD, Santa Ana, California. 

The Morbidity and Mortality Weekly Report (MMWR) Series is prepared by the Centers for Disease Control and Prevention (CDC) and is available free of charge in electronic format. To receive an electronic copy each week, visit MMWR at https://www.cdc.gov/mmwr/index.html.

Readers who have difficulty accessing this PDF file may access the HTML file at https://www.cdc.gov/mmwr/volumes/67/rr/rr6703a1.htm?s_ $\mathrm{cid}=\mathrm{rr} 6703 \mathrm{a} 1$ _w. Address all inquiries about the $M M W R$ Series, including material to be considered for publication, to Executive Editor, $M M W R$ Series, Mailstop E-90, CDC, 1600 Clifton Rd., N.E., Atlanta, GA 30329-4027 or to mmwrq@cdc.gov.

All material in the MMWR Series is in the public domain and may be used and reprinted without permission; citation as to source, however, is appreciated. Use of trade names and commercial sources is for identification only and does not imply endorsement by the U.S. Department of Health and Human Services. References to non-CDC sites on the Internet are provided as a service to MMWR readers and do not constitute or imply endorsement of these organizations or their programs by CDC or the U.S. Department of Health and Human Services. CDC is not responsible for the content of these sites. URL addresses listed in $M M W R$ were current as of the date of publication.

ISSN: 0149-2195 (Print) 